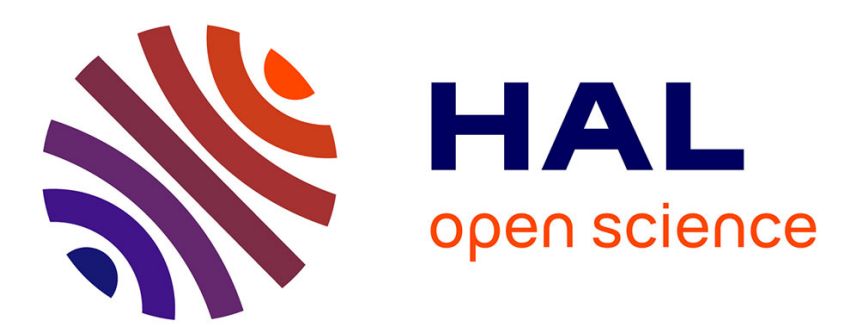

\title{
Eddy properties in the Southern California Current System
}

Fanny Chenillat, Peter J. S. Franks, Xavier Capet, Pascal Rivière, Nicolas

Grima, Bruno Blanke, Vincent Combes

\section{- To cite this version:}

Fanny Chenillat, Peter J. S. Franks, Xavier Capet, Pascal Rivière, Nicolas Grima, et al.. Eddy properties in the Southern California Current System. Ocean Dynamics, 2018, 68 (7), pp.761 - 777. 10.1007/s10236-018-1158-4 . hal-01835692

\section{HAL Id: hal-01835692 \\ https://hal.science/hal-01835692}

Submitted on 21 May 2020

HAL is a multi-disciplinary open access archive for the deposit and dissemination of scientific research documents, whether they are published or not. The documents may come from teaching and research institutions in France or abroad, or from public or private research centers.
L'archive ouverte pluridisciplinaire HAL, est destinée au dépôt et à la diffusion de documents scientifiques de niveau recherche, publiés ou non, émanant des établissements d'enseignement et de recherche français ou étrangers, des laboratoires publics ou privés. 


\section{UC San Diego}

UC San Diego Previously Published Works

Title

Eddy properties in the Southern California Current System

Permalink

https://escholarship.org/uc/item/0r89c709

Journal

Ocean Dynamics, 68(7)

ISSN

1616-7341

Authors

Chenillat, $F$

Franks, PJS

Capet, $\mathrm{X}$

et al.

Publication Date

2018-07-01

DOI

10.1007/s10236-018-1158-4

Peer reviewed 


\title{
Eddy properties in the Southern California Current System
}

\author{
Fanny Chenillat ${ }^{1,2}$ (D) Peter J. S. Franks ${ }^{1} \cdot$ Xavier Capet $^{3} \cdot$ Pascal Rivière $^{2} \cdot$ Nicolas Grima $^{4} \cdot$ Bruno Blanke $^{4}$. \\ Vincent Combes ${ }^{5}$
}

Received: 28 November 2017 / Accepted: 26 April 2018 / Published online: 18 May 2018

(C) Springer-Verlag GmbH Germany, part of Springer Nature 2018

\begin{abstract}
The California Current System (CCS) is an eastern boundary upwelling system characterized by strong eddies that are often generated at the coast. These eddies contribute to intense, long-distance cross-shelf transport of upwelled water with enhanced biological activity. However, the mechanisms of formation of such coastal eddies, and more importantly their capacity to trap and transport tracers, are poorly understood. Their unpredictability and strong dynamics leave us with an incomplete picture of the physical and biological processes at work, their effects on coastal export, lateral water exchange among eddies and their surrounding waters, and how long and how far these eddies remain coherent structures. Focusing our analysis on the southern part of the CCS, we find a predominance of cyclonic eddies, with a 25-km radius and a SSH amplitude of $6 \mathrm{~cm}$. They are formed near shore and travel slightly northwest offshore for $\sim 190$ days at $\sim 2 \mathrm{~km} \mathrm{day}^{-1}$. We then study one particular, representative cyclonic eddy using a combined Lagrangian and Eulerian numerical approach to characterize its kinematics. Formed near shore, this eddy trapped a core made up of $\sim 67 \%$ California Current waters and $\sim 33 \%$ California Undercurrent waters. This core was surrounded by other waters while the eddy detached from the coast, leaving the oldest waters at the eddy's core and the younger waters toward the edge. The eddy traveled several months as a coherent structure, with only limited lateral exchange within the eddy.
\end{abstract}

Keywords California upwelling system $\cdot$ Mesoscale eddies $\cdot$ Eddy dynamics $\cdot$ Lagrangian study $\cdot$ Numerical study

Responsible Editor: Alejandro Orfila

Fanny Chenillat

fannychenillat@univ-brest.fr

1 Integrative Oceanography Division, Scripps Institution of Oceanography, University of California San Diego, La Jolla, California, USA

2 Laboratoire des Sciences de l'Environnement Marin (LEMAR), UMR 6539 CNRS-Ifremer-IRD-UBO, Institut Universitaire Européen de la Mer (IUEM), Plouzané, France

3 Laboratoire d'Océanographie et du Climat (LOCEAN), CNRS-UPMC-IRD-MNHN, Institut Pierre Simon Laplace (IPSL), Paris, France

4 Laboratoire d'Océanographie Physique et Spatiale (LOPS), UMR 6523 CNRS-Ifremer-IRD-UBO, IUEM, Plouzané, France

5 College of Earth, Ocean and Atmospheric Sciences, Oregon State University, Corvallis, Oregon, USA

\section{Introduction}

The California Current System (CCS) is one of the most extensively studied eastern boundary upwelling systems (EBUS) (Bograd and Lynn 2003). Driven by the upwelling of cold, salty, nutrient-rich water at the coast, the CCS is among the most productive coastal ecosystems, supporting many economically important fisheries (FAO 2009). This upwelled coastal water creates strong cross-shore gradients influenced by both cross-shore Ekman transport and intense mesoscale activity (Capet et al. 2008c; Chaigneau et al. 2009; Sangrà et al. 2009; Combes et al. 2013).

This mesoscale activity is the focus of the present study. It is generated through various processes within a $\sim 700-\mathrm{km}-$ wide band along the coast (Kahru et al. 2012; Chaigneau et al. 2009). However, a significant fraction of that mesoscale activity is generated near shore (Marchesiello et al. 2003; Chaigneau et al. 2009) in response to wind forcing (ParesSierra et al. 1993; Batteen 1997) and instabilities of boundary currents (Batteen et al. 2003; Marchesiello et al. 2003; Colas et al. 2013) including interactions between topography and 
currents (Hickey 1998; Hickey et al. 2003; Caldeira et al. 2005; Dong et al. 2009). Eddies are known to enhance biological activity, driving high chlorophyll-a concentrations, high zooplankton biomass, and intense sardine spawning (Hayward and Venrick 1998; Checkley et al. 2000; Logerwell et al. 2001; Almazán-Becerril et al. 2012; Chenillat et al. 2015, 2016). This locally enhanced productivity is often transported far from its coastal origin.

Despite the large number of studies and observations in the CCS and other EBUS, the ecological roles of coastal eddies in upwelling systems are poorly documented. Recent studies have shown that eddies in the CCS are responsible for the offshore transport of coastal, nutrient-rich water and the redistribution of biogeochemical components through advection and diffusion (Gruber et al. 2011; Stramma et al. 2013) reach similar conclusions in the Humboldt Current System; Chenillat et al. 2016). However, the mechanisms of formation of such coastal eddies, and, perhaps, more importantly their capacity to trap and transport tracers, are poorly understood, mainly due to the difficulties of studying these features at sea. The ubiquity of mesoscale features leaves us with a very incomplete picture of the physical and biological processes controlling planktonic ecosystems in these systems.

Numerous techniques have been developed to characterize eddy properties including Eulerian approaches (e.g., Chelton et al. 2011) and Lagrangian methods (e.g., d'Ovidio et al. 2004). Such techniques have been used in various oceanic systems (e.g., Northeast Atlantic (Lehahn et al. 2007), PeruChile upwelling system (Chaigneau et al. 2008, 2011), western Gulf of Lion (Nencioli et al. 2011)), but only a few studies focused on eddies of the CCS (e.g., Chaigneau et al. 2009; Kurian et al. 2011). These latter studies averaged eddy characteristics over the entire CCS. However, the CCS has strong latitudinal variability, e.g., due to the alongshore wind gradient that drives a variable coastal upwelling from north to south (Checkley and Barth 2009). This latitudinal variability can directly impact the ecological role of eddies depending on where the eddies were formed. Finally, in all EBUS, the role of eddies in transporting material across the shelf is still poorly understood (Beron-Vera et al. 2008). To better understand the effect of eddies on biological dynamics and transport, we seek to understand whether eddies are leaky and how long and how far they typically maintain their coherent signature in terms of water masses.

We focus our study on the Southern CCS (SCCS), south of Point Conception $\left(34.5^{\circ} \mathrm{N}\right)$. The SCCS is characterized by high mesoscale activity mainly caused by interactions between topography and currents (Hickey 1998; Hickey et al. 2003; Caldeira et al. 2005; Dong et al. 2009). The SCCS is also of major ecological importance (McClatchie 2014). Applying an eddy detection and tracking algorithm to an ocean circulation model (OCM) run for 10 years, we perform comprehensive analyses to elucidate the properties of eddies in the region and quantify their spatial and temporal dynamics. To untangle the mechanisms enabling eddies to efficiently transport coastal waters, we then study a particular eddy that was found to be representative of cyclonic eddies in the SCCS. Combining the OCM results with a Lagrangian particle-tracking tool enabled us to quantify the evolution of the eddy's hydrographic properties and gain new insights into the formation, development, movement, leakiness, and dissipation of this particular cyclonic eddy that formed at the coast. Section 2 describes the models and numerical experiments; Sect. 3 explores eddy activity in the SCCS and determines the properties of the most common eddies in the region. Section 4 presents the study of one particular eddy's dynamics and kinematics and gives some biological insights. Conclusions are given in Sect. 5.

\section{Methods}

\subsection{Ocean circulation model}

We investigate mesoscale dynamics in the SCCS using the Regional Ocean Modeling System (ROMS), a three-dimensional, free-surface, hydrostatic, eddy-resolving primitive equation ocean model (Shchepetkin and McWilliams 2005). The model is configured with $5-\mathrm{km}$ horizontal resolution (as in Capet et al. (2008b)) and 32 vertical $\sigma$-coordinate levels, with higher resolution near the surface to resolve upper ocean physics. The grid is rotated to follow the general orientation of the west coast of the USA. The domain covers the entire CCS, from the coast to $1500 \mathrm{~km}$ offshore and from southern Canada $\left(50^{\circ} \mathrm{N}\right)$ to southern Baja California, Mexico $\left(24^{\circ} \mathrm{N}\right)$. The bathymetry is derived from etopo2 (http://www.ngdc.noaa. gov/mgg/global/etopo2.html) following the procedure of Penven et al. (2008). The physical boundary conditions, initial conditions, and surface forcings used in this study are derived from monthly climatologies. They are the same as in Capet et al. (2008b) who used the Comprehensive OceanAtmosphere Dataset (COADS) for surface fluxes, except for temperature data that were obtained from Advanced Very High Resolution Radiometer (AVHRR). QuikSCAT satellite scatterometer data for the period 2000-2008 were used as a monthly climatology for the wind forcing. Boundary conditions come from the Simple Ocean Data Assimilation (SODA) model (Carton and Giese 2008).

We ran a 40-year spin-up of the physical model. The final state of the physical spin-up was then used as the initial condition of a final 10-year run. Five-day averages of physical variables were archived and used to explore the main eddy statistics in the SCCS. In addition, we increased the output frequency to a daily average from the first 2 years of the final run (Y1 and Y2 hereafter) to perform Lagrangian analyses and passive tracer experiments. 
This high-resolution configuration of ROMS has previously been used to successfully explore mesoscale and submesoscale properties of the CCS (Capet et al. 2008c, 2008d; Kurian et al. 2011; Colas et al. 2013). Our solution shows realistic, coherent surface mesoscale activity (as in Kurian et al. (2011)), including permanent eddies generated from the California Current (Strub and James 2000; Centurioni et al. 2008) and coastal eddies formed through baroclinic instabilities in the SCCS (Capet et al. 2004).

\subsection{General eddy dynamic approach}

We begin by quantifying the overall statistics of eddies in the SCCS using eddy detection, eddy tracking, and composite analysis of eddy properties.

\subsubsection{Eddy detection}

To quantify mesoscale eddy properties from the 10-year run, we use the standard Okubo-Weiss method (Okubo 1970; Weiss 1991; Isern-Fontanet et al. 2003; Morrow et al. 2004; Chelton et al. 2007; Kurian et al. 2011; Frenger et al. 2013), which is based on the computation of Okubo-Weiss parameter $(W)$ :

$W=S_{n}^{2}+S_{s}^{2}-\zeta^{2}$,

where $S_{n}$ and $S_{s}$ are the normal and shear components of the strain and $\zeta$ the relative vorticity of the flow. These quantities are defined by

$S_{n}=\frac{\partial u}{\partial x}-\frac{\partial v}{\partial y}, \quad S_{s}=\frac{\partial v}{\partial x}+\frac{\partial u}{\partial y} \quad, \quad \zeta=\frac{\partial v}{\partial x}-\frac{\partial u}{\partial y}$,

respectively, where $u$ and $v$ are the eastward and the northward velocities. Potential location of eddies is given by a vorticitydominant $W$ field, where the rotation of the flow dominates over its deformation. This corresponds to negative values of $W$; we chose a threshold value of $-5 \times 10^{-11} \mathrm{~s}^{-2}$ to identify eddy cores (Chelton et al. 2007), i.e., the part of the eddy that is in solid body rotation. To remove non-eddy structures from the analysis, we used a shape test (Kurian et al. 2011) that consisted of fitting a circle over each detected entity, accepting features with a shape error less than $40 \%$ (see details in Kurian et al. (2011)) and with a minimum radius of $15 \mathrm{~km}$. The radius $R$, position, and polarity (cyclonic or anticyclonic) of eddies passing these criteria were archived.

\subsubsection{Eddy tracking}

An automated procedure was used to track eddies: eddy center positions and radii at consecutive time steps were compared. To avoid the algorithm switching between different eddies, eddies must not travel more than one eddy diameter between the consecutive time steps of the identification process. Only long-lived ( $>90$ days) eddies were analyzed, to provide a clear synthetic view of the lateral transport by eddies.

\subsubsection{Composite analysis}

To quantify the vertical structure of physical properties in the eddies, we performed a comprehensive composite analysis on all detected eddies. To include the eddy core and the area surrounding the eddy, we extracted the eddy properties over a cross-shore transect centered on the eddy from $-3 R$ to $+3 R$ (with $R$ the radius of the eddy core). The horizontal (radial) coordinates were then normalized by the radius $R$ of each eddy, and physical variables were averaged over all the eddies in this normalized coordinate system (eddy center at 0 and edge of the eddy core at \pm 1 ). These normalized distributions included temperature, salinity, and vorticity. We computed the eddy anomaly, at any given time and depth level, for any given field by removing the horizontal average of the fields from $3 R$ to $+3 R$ as in Kurian et al. (2011). This method tends to be more robust than the "differential anomaly" (Simpson et al. 1984) which consists in removing the value in the surrounding waters. Indeed, with our method, we remove the cross-shore trends that are common in coastal upwelling system (see the introduction).

\subsection{Study of eddy C01-2}

The second part of this study aims to investigate the eddy kinematics and dynamics of one particular eddy - representative of the SCCS - using a Lagrangian approach and a passive tracer as follows. This cyclonic eddy was spawned in January of Y2 in the model, and was thus named eddy C01-2.

\subsubsection{Lagrangian modeling}

To quantify the eddy kinematics, we performed Lagrangian analyses using the offline mass-preserving algorithm Ariane (Blanke and Raynaud 1997; Blanke et al. 1999). Using Eulerian velocity fields - here the daily archive of the first 2 years of the simulation-Ariane computes Lagrangian trajectories of numerical floats (particles), tracking the water properties (salinity, temperature, density, and depth) along the trajectories.

The Lagrangian experiments were conducted within the SCCS $\left(29-35^{\circ} \mathrm{N}\right)$, from the coast to $800 \mathrm{~km}$ offshore. This study area was chosen far enough from the model boundaries not to be contaminated by the open boundary condition procedure (Marchesiello et al. 2001) that relies on a prescribed external forcing.

An upstream phase consisted in releasing 210 particles each month along the model coastline (i.e., in the first ocean model grid cell west of the coast) from $29.2^{\circ} \mathrm{N}$ to $33.1^{\circ} \mathrm{N}$, 
from the surface to a maximum of 200-m depth, depending on topography. These 210 particles were released on the first day of each month from September Y1 to February Y2 and integrated forward in time until 30 March Y2. The region and the period of the release corresponded to the formation of cyclonic eddy C01-2 (see Sect. 4.1). A total of 1260 particles were thus released in the experiments. Among them, 843 became trapped in eddy C01-2 and were analyzed in this study, using additional Lagrangian integrations: (i) we followed them backward in time for 210 days to 1 September Y1 when C01-2 began to form and (ii) we tracked them forward in time for 120 days until 30 July Y2 when the eddy signature dissipated (see Sect. 4.1).

\subsubsection{Passive tracer experiment}

To track the water trapped in eddy C01-2 and quantify its degree of leakiness, we performed a passive tracer experiment. We released six independent tracers, each following the same advection-diffusion equation as for temperature and salinity. Each tracer concentration was set to 1 on 31 December Y1 within eddy C01-2. Tracers 1, 2 and 3 were released within the entire eddy from the surface to $60 \mathrm{~m}$, to $120 \mathrm{~m}$, and to $180 \mathrm{~m}$, respectively. Tracers 4,5 , and 6 were released within the core of the eddy and from the surface to $60 \mathrm{~m}$, to $120 \mathrm{~m}$, and to $180 \mathrm{~m}$, respectively. For this experiment, the core was defined by the $W$ parameter, whereas the edge was defined by the closed contours of SSH, with a threshold of $-4 \mathrm{~cm}$. Note that the SSH used here takes into account the mean dynamic topography (MDT, i.e., the longterm time mean sea level with respect to the geopotential surface). In the SCCS, the MDT is approx. $-4 \mathrm{~cm}$ and presents low spatial variability (Centurioni et al. 2008); thus, a SSH threshold of $-4 \mathrm{~cm}$ to delimit eddies would correspond to a sea-level anomaly threshold of $0 \mathrm{~cm}$, as expected.

\section{Eddy properties}

Following on the work of Kurian et al. (2011) who gave a detailed description of eddy properties in the entire CCS, we define the properties of the mesoscale eddies in the SCCS. This analysis will help to determine the spatial and temporal characteristics of eddies in the region in terms of their structure, hydrographic properties, and generation.

Applying the $W$ parameter method (Sect. 2.2) to the 10year-long model run with a 5-day archiving frequency, we detected a total of 7004 eddies, with a predominance of cyclonic eddies (65\%) compared to anticyclonic eddies (35\%) as previously observed in the region (Owen 1980; Stegmann and Schwing 2007; Kurian et al. 2011; Combes et al. 2013). Approximately $50 \%$ of eddies were found within a $200-\mathrm{km}$ coastal band, with a maximum frequency of occurrence at
$50 \mathrm{~km}$ from the coast and decreasing offshore (Fig. 1a), similar to the entire CCS region (Kurian et al. 2011). This is consistent with the formation of eddies near shore; as they propagate westward (Kelly et al. 1998; Strub and James 2000), they naturally decay due to friction and/or eddy-eddy interactions (Samelson et al. 2014), or deepen, losing their surface signature (Barth et al. 2002; Bograd and Mantyla 2005; Pegliasco et al. 2015).

We compare both the spatial and temporal frequencies of occurrence of cyclonic and anticyclonic eddies by computing

a)

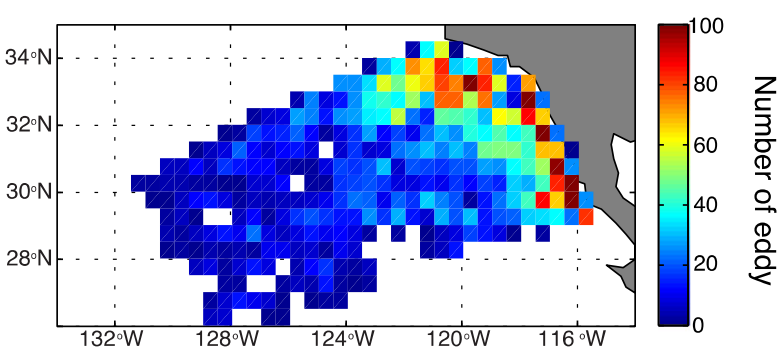

b)

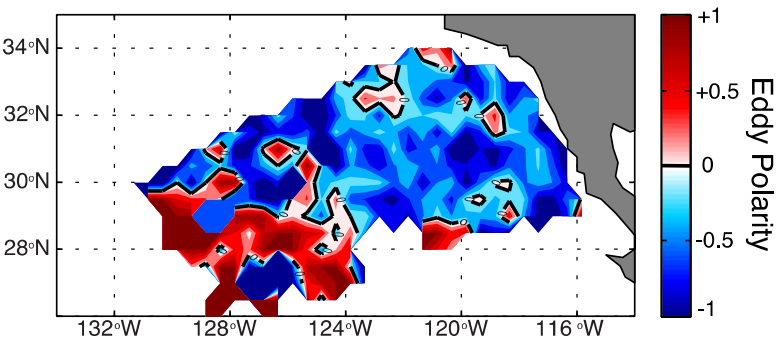

c)

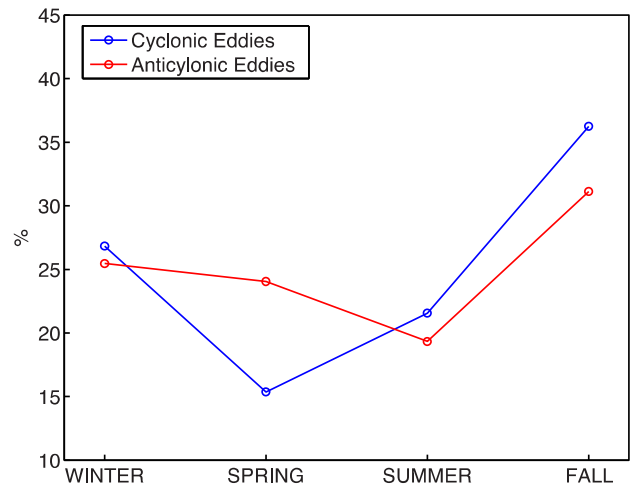

d)

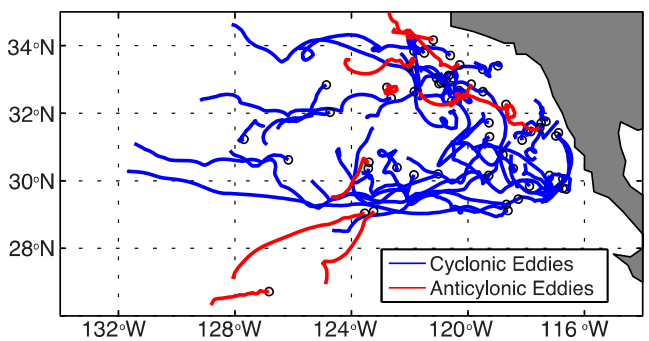

Fig. 1 Eddy detection and tracking in the Southern CCS. a Eddy occurrence. b Eddy polarity $((\mathrm{Na}-\mathrm{Nc}) /(\mathrm{Na}+\mathrm{Nc})$, with $\mathrm{Na}$ and $\mathrm{Nc}$ the total number of individual cyclonic (4567) and anticyclonic (2437) eddies). c Seasonal percentages of cyclones (blue) and anticyclonic (red) eddies found in the 50-km coastal band. $\mathbf{d}$ Tracks of long-lived ( $>90$ days) cyclonic $(n=42)$ and anticyclonic $(n=11)$ eddies 
the number of anticyclones $\left(N_{a}\right)$ and cyclones $\left(N_{c}\right)$, normalized by the number of total eddies, i.e., $\left(N_{a}-N_{c}\right) /\left(N_{a}+N_{c}\right)$ (Chaigneau et al. 2009; Kurian et al. 2011) (Fig. 1b). The numbers of eddies $\left(N_{a}\right.$ and $\left.N_{c}\right)$ are counted in $1^{\circ} \times 1^{\circ}$ windows. Up to several hundred kilometers offshore, cyclones were dominant compared to anticyclones (Fig. 1b), consistent with previous observations from satellites (Stegmann and Schwing 2007) and models (Kurian et al. 2011). The eddy core radius was $\sim 25 \pm 8 \mathrm{~km}$ (mean \pm standard deviation) for cyclones and $\sim 20 \pm 6 \mathrm{~km}$ for anticyclones.

We found a clear seasonal cycle of eddy occurrence within the 50-km coastal band, with a peak for both eddy polarities in the fall (Fig. 1c). This is consistent with higher mesoscale activity found during the fall from analyses of altimetry data in the SCCS (Strub and James 2000). However, the same analysis of eddies up to several thousand kilometers offshore does not show significant seasonality. This lack of offshore seasonality is due to the strong decay of coastal eddies offshore.

Using the eddy tracking method, more cyclonic eddies (42) than anticyclonic eddies (11) were followed in the Southern CCS (Fig. 1d). This imbalance is consistent with the total number of individual eddies and previous studies (Stegmann and Schwing 2007; Kurian et al. 2011), and can be explained by two mechanisms: (i) according to Kurian et al. (2011), most anticyclonic eddies in this region are subsurface eddies, i.e., their maximum signature is around 400-m depth giving an uneven surface signature; (ii) while traveling offshore, eddies can deepen (Barth et al. 2002; Bograd and Mantyla 2005; Pegliasco et al. 2015), losing their surface signature. These two reasons also explain why we found differences in eddy lifetimes: cyclonic eddies last $\sim 190$ days on average, vs. 120 days for anticyclonic eddies. Cyclones and anticyclones travel westward with a poleward and equatorward component, respectively. This asymmetric deflection has been observed from satellite data (Morrow et al. 2004; Chelton et al. 2007, 2011b) and models (Kurian et al. 2011), and has been related to the beta drift effect (McWilliams and Flierl 1979; Cushman-Roisin 1994).

The average vertical temperature, salinity, and vorticity structure of both cyclonic and anticyclonic eddies were obtained using composite analysis of all eddies of the CCS (Fig. 2). These composites are created from cross-shore sections through the eddy core, normal to the mean orientation of the coast. Because the eddy fields are close to being radially symmetric, these composites are representative of the entire eddy. Cyclonic eddies show a clear doming of isotherms and isohalines above $200 \mathrm{~m}$ (Fig. 2a, b, left column), with a decrease of the amplitude of the doming with depth. Isotherms and isohalines in anticyclonic eddies present a lesspronounced deepening than the doming in cyclonic eddies (Fig. 2a, b, right column). The eddy anomaly in cyclonic eddies for temperature and salinity $\left(-0.60{ }^{\circ} \mathrm{C}\right.$ and +

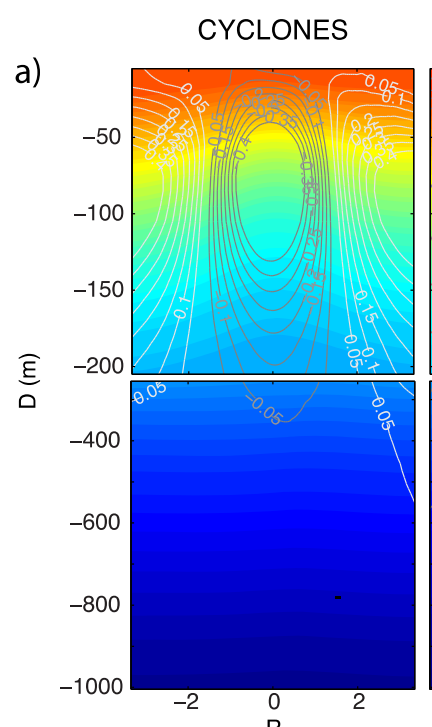

ANTICYCLONES
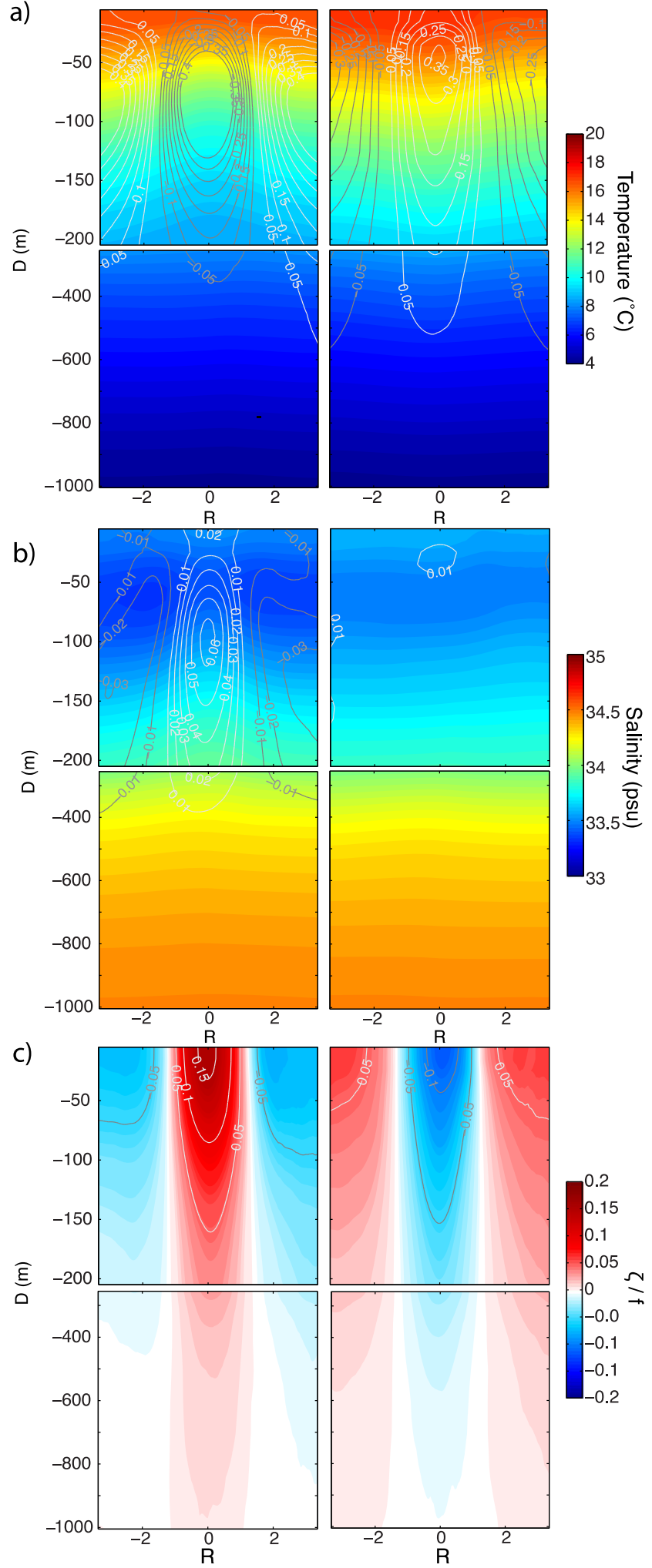

Fig. 2 Composite analysis of cyclonic (left column) and anticyclonic (right column) eddies showing a temperature, b salinity, and $\mathbf{c}$ vorticity $(\zeta / f)$. For temperature and salinity, the colors represent the mean and the contours the anomaly relative to the waters outside the eddy. For the vorticity, both colors and contours represent the anomaly 
$0.06 \mathrm{psu}$, respectively) appears at $\sim 100$-m depth. In anticyclones, the temperature and salinity anomalies $\left(+0.35^{\circ} \mathrm{C}\right.$ and +0.01 psu, respectively) appear at $\sim 50$-m depth. For both eddy polarities, these anomalies are visible down to $400-\mathrm{m}$ depth. The greatest anomalies in vorticity appear at the surface: $+0.15 \mathrm{~s}^{-1}$ for cyclonic eddies and $-0.10 \mathrm{~s}^{-1}$ for anticyclonic eddies (Fig. 2c). Similar composite anomaly analyses have been performed over the entire CCS (Kurian et al. 2011) and show similar results for temperature and vorticity; results for salinity differ probably due to the possible inclusion of subsurface anticyclones in our diagnostics. The eddy identification used in our study, however, does not identify subsurface, intrathermocline eddies that do not have a clear surface signature. Generated by instabilities of the California Undercurrent (CUC), intrathermocline eddies are usually anticyclonic with a clear subsurface salinity maximum originating from the CUC (Kurian et al. 2011). Note that while using the identification method described above, the average eddy diameter $(2 R)$ is $50 \mathrm{~km}$, whereas using the extent of the tracer anomalies in Fig. $2(\sim 2 \times 1.8 R)$, the average eddy diameter is $\sim 80 \mathrm{~km}$.

On average, T-S plots from each eddy polarity correspond well with data from the California Cooperative Oceanic Fisheries Investigations (CalCOFI) program (Kim et al. 2005), and the $C$ shape of the T-S curves demonstrates that there were at least three water masses in each eddy type (Fig. 3). Between 2 and $20^{\circ} \mathrm{C}$ and 33 and 34.5 psu, we can identify three different source waters, characteristic of this region: the shallow warm, salty Eastern North Pacific Transition Water (ENPTW); the deep, cold and salty California Intermediate Water (CIW), likely associated with coastal upwelling; and the shallow cold and fresh Pacific Subarctic Upper Water (PSUW), associated with the

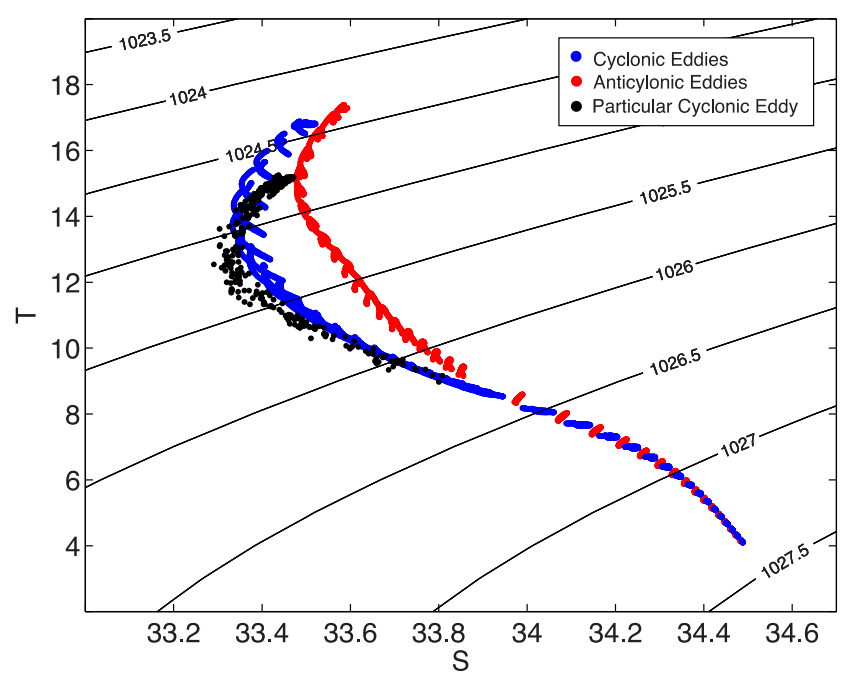

Fig. 3 Temperature-salinity (T-S) diagram computed for the averaged cyclonic (blue) and anticyclonic (red) eddies (within the core, from the surface to $1000-\mathrm{m}$ depth) from the composite analysis and for the Lagrangian particles trapped in C01-2 (black) equatorward California Current (CC) (Emery and Meincke 1986; Emery 2001). Along the coast, flow instabilities produce filaments and eddies that trap and mix these water masses together. There are some differences in the T-S curves of cyclones and anticyclones, particularly in the upper $200 \mathrm{~m}$. This is the result of different source waters or mixing processes in each type of eddy (see Sect. 4).

This general composite approach does not give access to estimates of how much of each water mass is trapped within eddies. In the following section, we quantify this using Lagrangian drifters.

\section{Analysis of eddy C01-2}

The aim of this section is to understand the details of the formation and life history of a typical eddy in the Southern CCS. A canonical eddy in the Southern CCS is cyclonic, is generated at the coast in the fall, has a core radius of $\sim 25 \mathrm{~km}$, and propagates offshore over $\sim 190$ days, at an average speed of $2 \mathrm{~km} \mathrm{day}^{-1}$. Here, we follow one particular eddy that meets all these criteria, from its early formation at the coast until its decay several thousand kilometers offshore. We characterize the eddy's hydrography, its source water masses, its circulation, and its vertical and horizontal kinematics, and discuss its potential impact on biology.

\subsection{Characterization of eddy C01-2}

From the 2-year-long daily-averaged run, we identified a typical cyclonic coastal eddy, named $\mathrm{C} 01-2$. We compare the characteristics of $\mathrm{C} 01-2$ to the canonical cyclonic eddy when the former had completely separated from the coast, i.e., in March Y2 (see below). The T-S plots of C01-2 and of the canonical cyclonic coastal eddy are very similar (Fig. 3). Vertical sections across the eddy C01-2 reveal an upward doming of isotherms, isohalines, and consequently isopycnals visible down to $200-\mathrm{m}$ depth, reflecting the eddy's cold, salty core (Fig. 4). These vertical profiles are very similar to the canonical cyclonic eddy temperature and salinity patterns (Fig. 2), despite a $2{ }^{\circ} \mathrm{C}$ colder sea surface temperature in C01-2 than the canonical eddy. As in the composite analysis, in the southwest portion of C01-2 and above the $\sigma=26.5$ isopycnal, a subsurface salinity minimum is visible, likely due to a deepening of the equatorward $\mathrm{CC}$ as it is deflected by the CUC at this latitude (see Sect. 4.3). As expected from the isopycnal doming, the mixed layer depth (MLD, based on the maximum temperature gradient in the upper $200 \mathrm{~m}$ ) is shallower inside C01-2 than outside (Fig. 4b). Though the eddy signature is detectable at the surface with $\mathrm{SSH}$, vorticity, and the Okubo-Weiss field ( $W$ ) (Fig. 4a), it is less clear in the sea surface temperature (Fig. 4b). This is consistent with the 

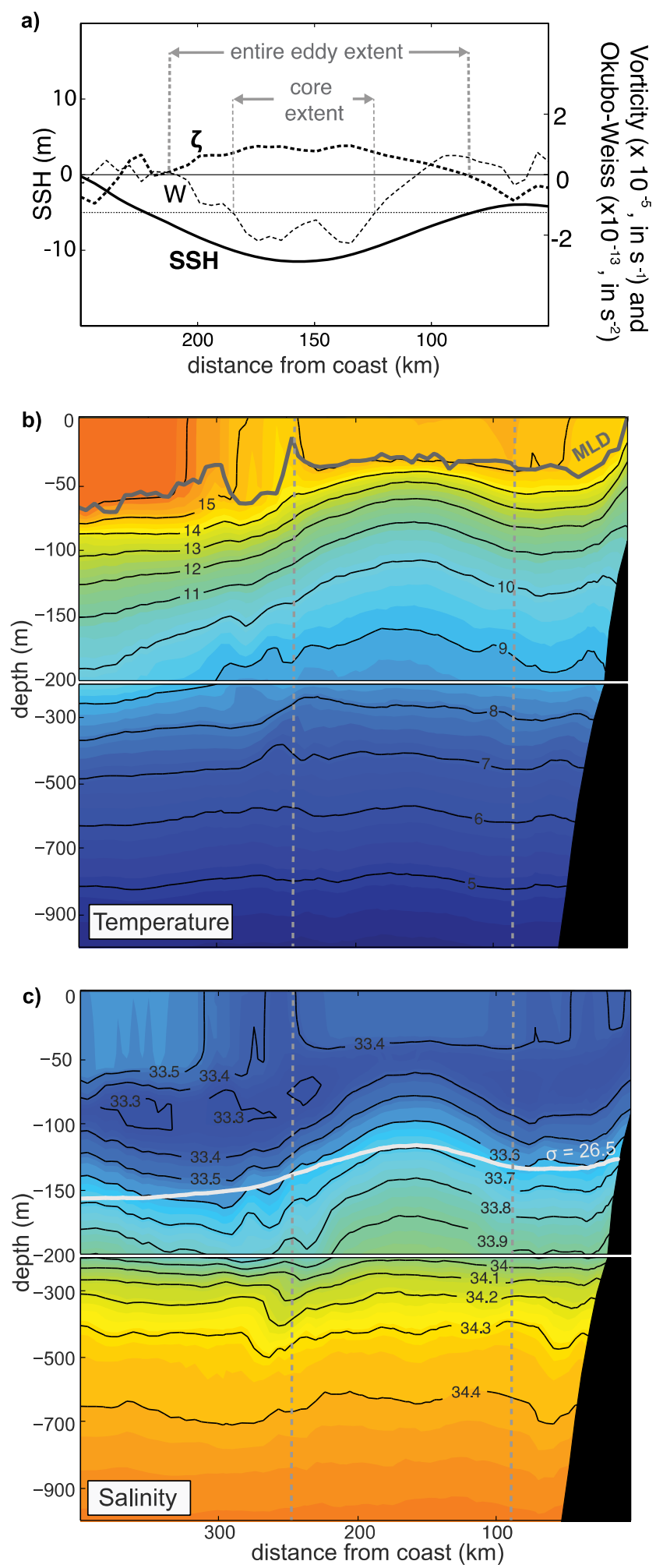

Fig. 4 Cross-shore section across the cyclonic eddy C01-2 on 30 March Y2. a SSH anomaly (cm, solid line), vorticity ( $\zeta$ in s $^{-1}$, bold dashed line), and Okubo-Weiss parameter ( $\mathrm{W}$ in $\mathrm{s}^{-2}$, thin dashed line). b Temperature $\left({ }^{\circ} \mathrm{C}\right)$ and mixed layer depth (MLD) based on the temperature gradient (in dark gray). c Salinity and depth of the $\sigma=26.5$ isopycnal (in light gray). Vertical light gray dotted lines correspond to the extent of the entire eddy composite analyses, which shows only a weak horizontal gradient in temperature near the surface.

The outer boundary of C01-2 can be described using SSH anomalies and relative vorticity (Doglioli et al. 2007), while $W$ is useful to detect the eddy core (see Sect. 2.2.1). The SSH threshold of $-4 \mathrm{~cm}$ was spatially correlated with changes in the signs of vorticity and $W$ (Fig. 4a). Using SSH and vorticity to define the edge of the eddy (Chaigneau et al. 2009) gives a radius of $\sim 70 \mathrm{~km}$ in March $\mathrm{Y} 2$. On the other hand, the threshold criterion of $W$ gives a radius of $\sim 30 \mathrm{~km}$ for the eddy core. This was close to the average core radius found for cyclonic eddies in the Southern CCS (see Sect. 3). The curl and the deformation rate (the strain) were positive in the core $\left(10^{-5}\right.$ and $0.3 \times 10^{-5} \mathrm{~m} \mathrm{~s}^{-2}$, respectively).

C01-2 was formed from a meander in the SCCS at the coast around $32^{\circ} 30^{\prime} \mathrm{N}$, between San Diego (California) and Ensenada (Mexico) in early fall of the first year (Y1) of the simulation (Fig. 5a). The meander grew progressively, moving away from the coast (Fig. 5b), forming eddy C01-2 around November Y1, i.e., in fall, the period favorable for the formation of coastal eddies (Sect. 3). C01-2 was linked to the coast until January Y2 (Fig. 5c). By March, Y2 C01-2 had completely separated from the coast and its SSH anomaly signature shows it to be an established structure (Fig. 5d). From May to July, Y2 C01-2 lost its shape and stretched (Fig. 5e) through interactions with adjacent mesoscale features, with which it finally merged (Fig. 5f). These interactions were increasingly detrimental to the coherence of C01-2 because (i) the curl and the strain of C01-2 weakened with time and (ii) the adjacent eddy field had a higher curl and strain than C01-2 at later times (not shown). The period from meander formation to eddy dissipation was 8-9 months. However, C01-2 was isolated and coherent for about 67 months (180-210 days), the average lifetime of cyclonic eddies in the SCCS (Sect. 3).

From January to March Y2, C01-2 moved southwest, $200 \mathrm{~km}$ from shore, angling to northwest around March Y2 once it was well formed, until it disappeared around July Y2, after traveling $\sim 1000 \mathrm{~km}$. This changing trajectory is consistent with our eddy tracking (Fig. 1d) and that of Kurian et al. (2011) (see their Fig. 10). The reasons for C01-2's southward propagation are unclear, but may be a result of its formation dynamics (Sect. 3). The poleward propagation is driven by the beta drift effect (Sect. 3). The average translation velocity of C01-2 was $\sim 2.2 \mathrm{~km} \mathrm{day}^{-1}$, similar to other eddies in the Southern CCS (Sect. 3).

During the eddy's lifetime, the core radius initially increased through March Y2 when it reached $\sim 45 \mathrm{~km}$, and then decreased. The initial increase was associated with an inverse energy cascade as the eddy matured (Kurian et al. 2011): both curl and strain were positive $\left(>10^{-5} \mathrm{~m} \mathrm{~s}^{-2}\right)$ while the eddy grew, but the curl decreased to $0 \mathrm{~m} \mathrm{~s}^{-2}$ and the strain became negative as the eddy decayed. During most of its lifetime, the 

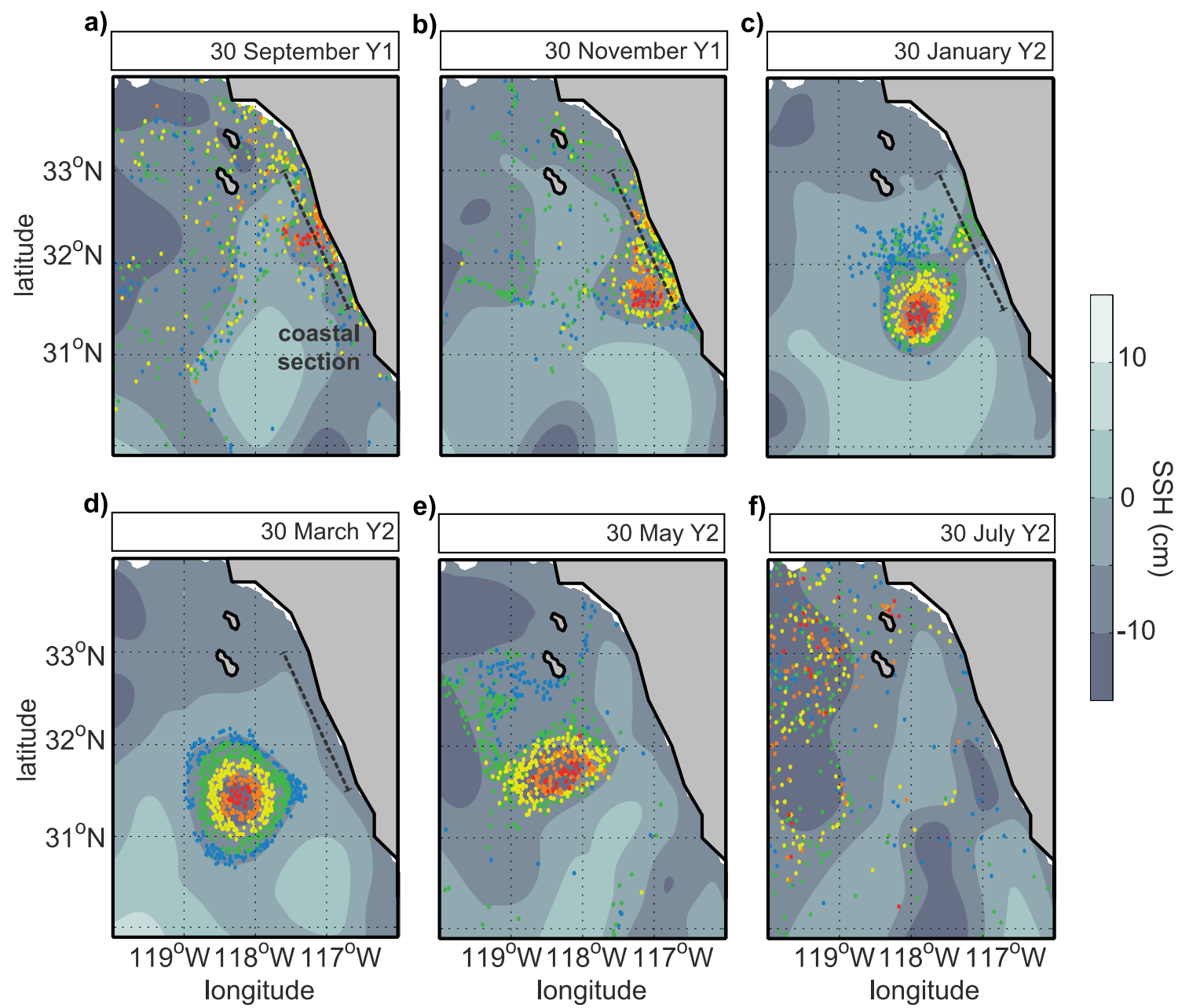

Fig. 5 Bimonthly daily mean modeled SSH (gray scale, in $\mathrm{cm}$ ). On 30 March Y2 (d), Lagrangian particles were initialized in C01-2. Different pools were colored based on their SSH ranges (see Table 1) and tracked backward $(\mathbf{a}-\mathbf{c})$ and forward $(\mathbf{e}, \mathbf{f})$ in time using the Ariane Lagrangian module. Each dot corresponds to one particle. The color of each particle

pool is used consistently for Figs. 6, 7, and 8. The dashed line in panels a to $\mathbf{d}$ indicates the coastal section through which particles passed before entering C01-2. Of the 1260 total particles in use, only the 843 particles that entered C01-2 are shown in the panels

eddy was highly non-linear, i.e., the rotation speed was on average two to four times higher than the translation speed (see Sect. 4.2).

\subsection{C01-2 kinematic processes and nested ring structure}

We explored the kinematics of eddy C01-2 using Lagrangian particle tracking. The upstream analyses showed that almost all the particles initialized near the model coastline and entrained into C01-2 moved north or south along the coast before being advected from the coast offshore to the eddy through a $135-\mathrm{km}$-long coastal section (Fig. 5a). This coastal section was used to select 843 particles (out of 1260 particles released) with trajectories from the coast to the eddy (Fig. 5ad). We performed two Lagrangian experiments with the particles found in C01-2 on 30 March Y2: (i) we followed them backward in time for 210 days to 1 September Y1 when C01-
2 began to form and (ii) we tracked them forward in time for 120 days until 30 July Y2 when the eddy signature dissipated. Together, these backward and forward tracks reveal the pathways taken by particles that became trapped in the eddy, and thus, the kinematics of the eddy as it formed moved away from the coast and dissipated (Fig. 5). In our analyses, we trace the sources of the particles, and their spatial arrangement and movement within $\mathrm{C} 01-2$.

To trace the spatial organization of water parcels within C01-2, the particles found in the eddy on 30 March Y2 (Fig. 5d) were divided into five pools based on SSH thresholds (Table 1), from the eddy core ( $\mathrm{SSH}<-11 \mathrm{~cm}$, or $-8 \mathrm{~cm}$ for corrected sea-level anomaly) to its edge ( $\mathrm{SSH}>-4 \mathrm{~cm}$, or $0 \mathrm{~cm}$ for corrected sea-level anomaly) (Fig. $5 \mathrm{~d}$ ). We chose $\mathrm{SSH}$ as a criterion to partition the eddy as it was spatially smoother than the vorticity or $W$, making the initial delimitation clearer. The particle depths roughly followed the isopycnals, which deepened from the core to the edge of the 
Table 1 Initialization of particles in the 30 March Y2 eddy, C01-2

\begin{tabular}{clll}
\hline Pool number & SSH minimum & SSH maximum & Number of particles \\
\hline 1 & & $-11 \mathrm{~cm}$ & 25 \\
2 & $-11 \mathrm{~cm}$ & $-10 \mathrm{~cm}$ & 82 \\
3 & $-10 \mathrm{~cm}$ & $-8 \mathrm{~cm}$ & 200 \\
4 & $-8 \mathrm{~cm}$ & $-6 \mathrm{~cm}$ & 311 \\
5 & $-6 \mathrm{~cm}$ & $-4 \mathrm{~cm}$ & 225 \\
\hline
\end{tabular}

Initial location and number of Lagrangian particles used in tracking the eddy kinematics in relation to SSH. Each pool of particles is initialized on 30 March Y2 in the cyclonic eddy, C01-2. Each SSH range corresponds to the location of the particle pool from the center (pool \#1) to the edge (pool \#5)

eddy (Fig. 6). The different particle pools showed that C01-2 formed from a meander near the coast around 30 September Y1 (Fig. 5a). At this time, most of the particles that subsequently entered C01-2 were spread over the SCCS region (Fig. 5a). During the 5 months C01-2 was forming and moving offshore, it grew by wrapping particles around its core, forming concentric annuli of particle ages, with the oldest particles at the center and the youngest at the outer edge of the eddy (Fig. 5b, c). Because of our experimental protocol, all the particles entered $\mathrm{C} 01-2$ after passing through the coastal section, though at different times which determined the average age of the particle pools (Table 2). They approached the coastal section from both the north and south. This entrainment from the coast to an eddy through a restricted coastal section has been previously observed in other numerical studies of coastal eddy formation (e.g., Batteen 1997; Capet and Carton 2004).

The particles formed rings around C01-2 with the oldest particles in the core and the youngest at the outer edge, following the $\sigma=25.0$ isopycnal (not shown). Based on the

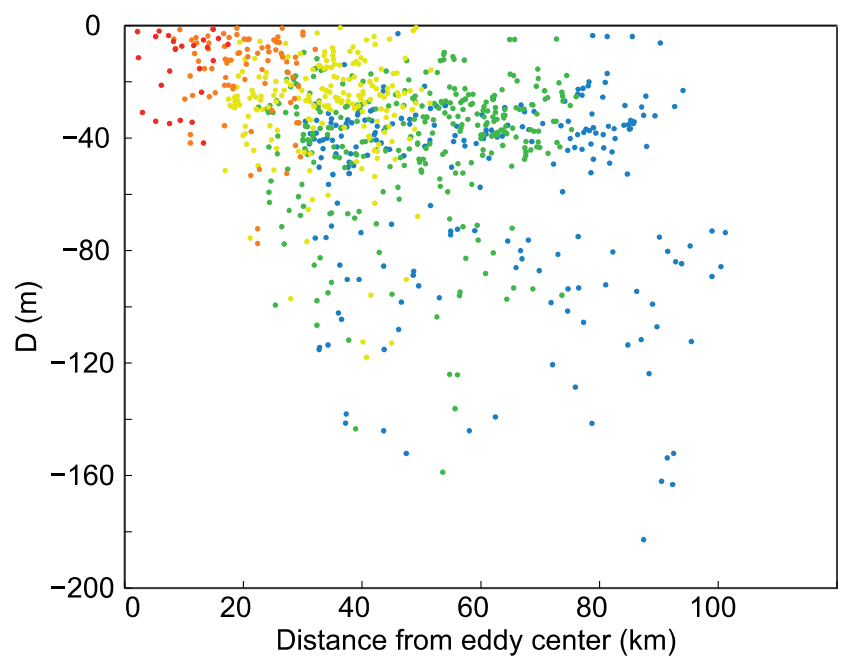

Fig. 6 Initial depths of the particles within C01-2 on 30 March Y2 as a function of distance from the eddy center. Refer to the Table 1 and Fig. 5 for the color code
Table 2 Age of coastal particles in the eddy C01-2, on 30 March Y2

\begin{tabular}{cc}
\hline Pool number & Age in days \\
\hline 1 & $175(20)$ \\
2 & $147(33)$ \\
3 & $108(17)$ \\
4 & $79(23)$ \\
5 & $90(20)$ \\
\hline
\end{tabular}

Average (standard deviation) age for each particle pool on 30 March Y2, in the cyclonic eddy, C01-2, obtained from the Lagrangian experiments. The age represents the time elapsed since the particles crossed the coastal section (represented in Fig. 3a-d) before entering the eddy

relatively constant average distance of individual particle pools from the eddy center (Fig. 7a, b), this pattern lasted at least 6 months. Furthermore, the low variance of these distances shows that radial exchanges among the particle pools were weak. Such low horizontal mixing within eddies is typical of coherent structures with high radial stability (Sangrà et al. 2005). Our Lagrangian method can be thought as a simplified version of both finite-space and finite-time Lyapunov exponents (d'Ovidio et al. 2004; Shadden et al. 2005). It enables us to delimit the eddy in space and time and provides additional information concerning its properties, in particular the effects of its rotation. Particles at the center of C01-2 (the oldest particles) made up to 20 revolutions around the core (Fig. 7c, d) with the outermost (youngest) particles entering the eddy later and making fewer than five revolutions. The center of C01-2 rotated faster than the edge, implying a radial shear of the rotational velocity. Moreover, the rotation rate of all parts of C01-2 decreased continuously as the eddy grew (Fig. 7e). When C01-2 formed in September Y1, the angular velocity (Fig. 7e) corresponded to about a full rotation every 7 days (i.e., an angular velocity of $\omega=$ 0.14 day $^{-1}$ ). By the time C01-2 detached from the coast around March Y2 (Fig. 5>d), the time for a full rotation increased to 17 days inside the core $\left(\omega=0.06\right.$ day $\left.^{-1}\right)$ and 50 days at the edge $\left(\omega=0.02\right.$ day $\left.^{-1}\right)$. This angular velocity corresponds to a rotational fluid speed $U$ of about 4 to $8 \mathrm{~km}$ day ${ }^{-1}$. With a translation speed $c$ of $\sim 2.2 \mathrm{~km} \mathrm{day}^{-1}$ (see Sect. 3), the ratio $U / c$ is greater than 1 implying that $C 01-2$ is non-linear; this non-linearity allows the eddy to maintain its coherent structure as it propagates offshore (Flierl 1981; Chelton et al. 2011). Moreover, the eddy core, composed of the two particle pools closest to the eddy center, was in approximate solidbody rotation (both pools had the same angular velocity $\omega$ (Sangrà et al. 2005)). C01-2 clearly showed a radial gradient involving decoupling of the core from the outer rings, which can be important in affecting the local biological dynamics. 
Fig. 7 Temporal evolution for each particle pool trapped in C01-2 of $\mathbf{a}, \mathbf{b}$ the distance from the eddy center, $\mathbf{c}, \mathbf{d}$ the number of revolutions made around the eddy center, and $\mathbf{e}, \mathbf{f}$ the corresponding angular velocity. The left column is the backward Lagrangian experiment from 30 March Y2, and the right column is the forward experiment. The number of revolutions is computed beginning from the average time the pool of particles crossed the coastal section. It is calculated by integrating angles around the eddy center along the particle path over consecutive time steps. The angular velocity is calculated from the time derivative of the number of revolutions. Solid lines and shaded areas represent the averages and standard deviations for each pool, respectively. Refer to the Table 1 and Fig. 5 for the color code
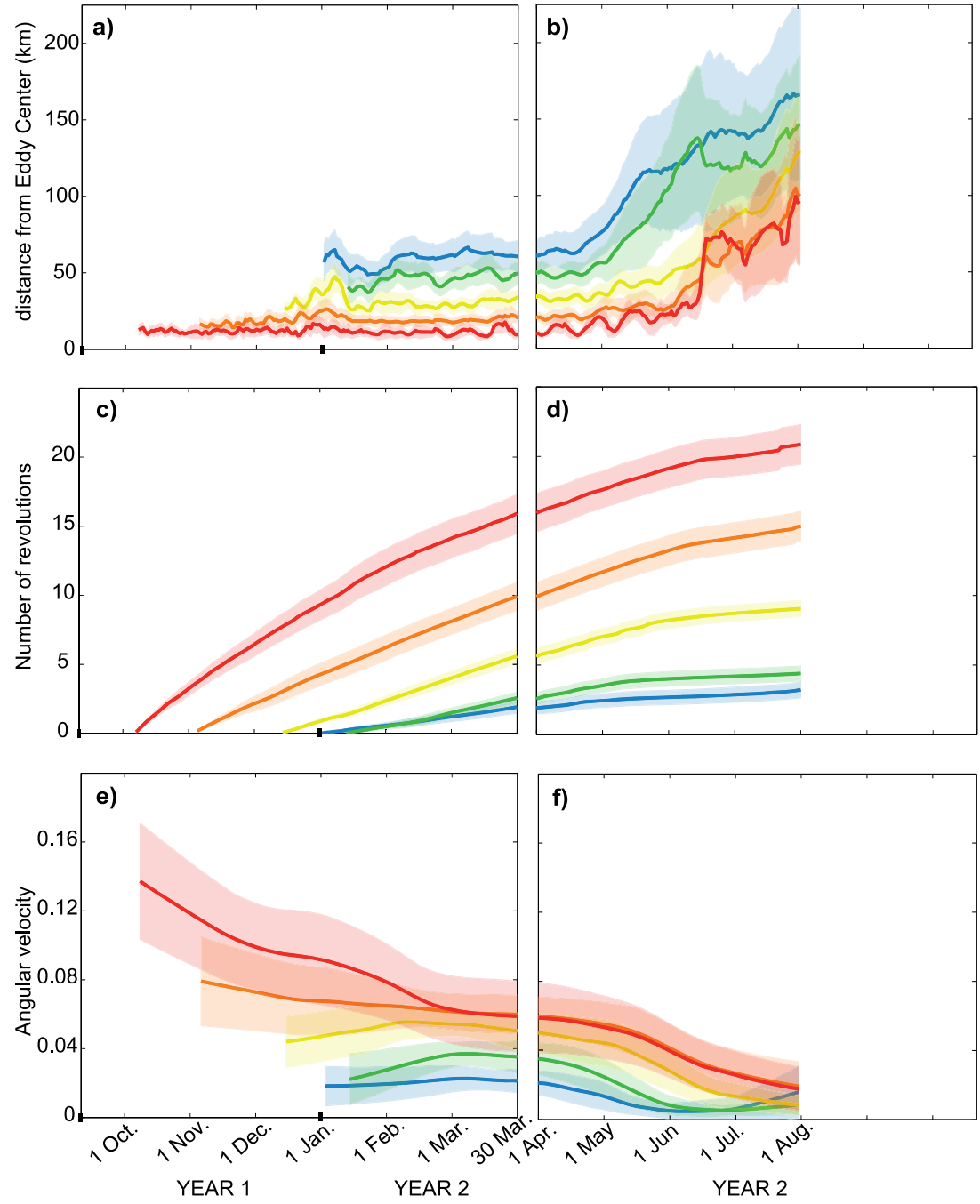

f)

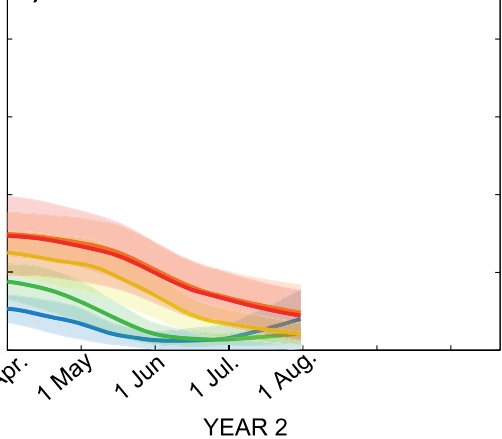

Once C01-2 had separated from the coast (Fig. 5d) it traveled offshore, still entraining some non-coastal particles that accumulated at the edge of the eddy (not shown). During this time, from March to May Y2, the eddy core stretched and compressed radially (Fig. 5e), showing 10 to 20-day oscillations of the average distance of the core pools from the eddy center (Fig. 7a, b). Despite these distortions, the rings of particles were still visible and coherent (Fig. 7a, b). Around May Y2 (Fig. 5e), the outermost particles began to leave C01-2, as shown by the abrupt increase of the distance from the eddy center of the outermost particle pools (Fig. 7b): the last particles trapped in the eddy were the first to leave. By 30 July Y2 (Fig. 5f), C01-2 had completely merged with two other mesoscale features. The consequence of this merging was to disperse the particles over the SCCS, dissipating the eddy's signature.

In addition to these Lagrangian experiments tracking the flux of coastal particles into the eddy, we ran experiments to determine the origins of particles that were in C01-2. New particles were initialized in C01-2 on 30 March Y2, and run backward in time to find their source. The initial particle positions for this experiment covered the vertical (defined by isopycnals) and horizontal (defined by different SSH criteria) extent of C01-2 (see Table 3 for the location and number of particles initialized in each case). The results (Table 3) show that $93.5 \%$ of the particles in the eddy core came from the coast; this percentage decreased when additional rings around the eddy were included (i.e., with increased distance from the eddy center), due to the incorporation of non-coastal particles as C01-2 grew and detached from the coast. Again, this is consistent with the generic properties of a cyclonic eddy: (i) a highly coherent core with low horizontal mixing (see above) and (ii) a tendency to wrap water around it as it grows.

\subsection{C01-2 water mass origins and vertical structure}

Recent in situ studies in EBUS have hypothesized that coastal eddies can entrain multiple water masses during their formation (Almazán-Becerril et al. 2012; Stramma et al. 2013). We tested this hypothesis by first computing the T-S properties of 
Table 3 Coastal composition of the eddy C01-2, on 30 March Y2

Pool number Percentage of particles intercepted by the coastal section

$\begin{array}{ll}1+2 & 93.5 \% \\ 1+2+3 & 81.0 \% \\ 1+2+3+4 & 71.7 \% \\ 1+2+3+4+5 & 70.0 \%\end{array}$

Percentage of Lagrangian particles that crossed the coastal section. In this experiment, Lagrangian particles were seeded horizontally and vertically at different locations inside the cyclonic eddy, C01-2, on 30 March Y2 (see Table 1), and followed backward in time to identify those that passed through the coastal section (represented in Fig. 3a-d)

the Lagrangian particles that became trapped in the eddy in the upper $200 \mathrm{~m}$ (Fig. 3). The T-S properties fit with the T-S diagram from the composite analysis, with a slight difference in surface water temperature as observed for the cross-shore temperature section (Fig. 2b, c). These similarities confirm that C01-2 contains different water masses, including water from the CC and CUC. Most eddies formed in this region originate from instabilities of currents flowing in opposite directions, in this case instabilities between the CC and CUC (Batteen 1997). Tracing the origins of our Lagrangian particles through backward experiments showed that C01-2 was formed from several sources (Fig. 8): $67 \%$ of the particles entering C01-2 came from the north and 33\% from the south. Particles from the north entered C01-2 at shallower depths ( 0 $50 \mathrm{~m})$ than particles originating from the south $(40-120 \mathrm{~m})$ (Fig. 8a, b), consistent with particles from the north originating from the PSUW (in the CC), while the particles from the south originated from the CIW (in the CUC).

The fates of the water masses trapped in C01-2 were tracked along the particle trajectories. The depths of each particle pool remained relatively constant (with a slight shoaling of the southern origin particles) showing that as C01-2 formed, it wrapped itself in progressively deeper source waters. The temperatures of particles entering from the north reflected the progression through the winter cooling and spring warming (Fig. 8c). These northern origin pools differed, however, in salinity (Fig. 8e), which reflected the progressively deeper (and saltier) origins of the particles outside the eddy over time. Particles entering C01-2 from the south were on average deeper than the northern particles (Fig. 8b, d, $\mathrm{f}$ ), creating a vertical gradient over time with the water properties of the northern origin particles (Sprintall and Cronin 2001). The salinity of the southern origin particles was similar among the pools, and the pools evolved in concert (Fig. 8f). Because of this, the temperatures of the different southern origin pools differed, reflecting variability of their origin with depth (Fig. 8d).

These similarities and differences among the northern and southern particles highlight the differences in radial mixing within C01-2. In the core - and regardless of the origin of the particles - the salinity and temperature variance of the two particle pools decreased, indicating mixing and local homogenization of the water masses (e.g., d'Ovidio et al. (2013), and references within). Low radial mixing at the outer edge of C01-2 is reflected in the persistently high variance among particle water properties there. Moreover, the last particles to enter C01-2 also tended to be the deepest, which is consistent with the downward-sloping isopycnals from the center of the eddy (Figs. 3, 6, and 8).

Here, we have shown the ability of a coastal eddy to trap water masses of different origins and properties and to keep them distinct for months while traveling several hundred kilometers in the SCCS. This is an essential element of conceptual views of coastal ocean functioning (Stramma et al. 2013). In this case study, the cyclonic eddy was able to trap and gather in its core northern and southern water sources with clearly different water properties. The northern water sources tended to remain shallower $(<20-\mathrm{m}$ depth) than southern water sources ( $>20-\mathrm{m}$ depth). Indeed, the deep southern water masses tend to be nutrient-rich compared to the shallow northern water masses. This may play a crucial role in subsequent biological dynamics inside the eddy.

\subsection{Eddy leakage}

The ability of an eddy to retain its waters depends on advection and diffusion in and around the eddy. In the previous section, using advection-only Lagrangian experiments, we found that $\mathrm{C} 01-2$ stayed coherent for about 5-6 months-keeping the different particle pools at a constant average distance from the eddy center. Using passive tracer experiments, we now focus on diffusive processes. The passive tracers were released in C01-2 on 31 December $\mathrm{Y} 1$ and followed until 31 August Y2 (Fig. 9a). From January Y2 until June Y2, the passive tracers changed very little (Fig. 9a), staying coherent within the eddy with only weak diffusive mixing with the surrounding waters.

To quantify the horizontal diffusivity of the eddy, for each experiment, we integrated the tracer concentration vertically and in the alongshore direction, giving a onedimensional cross-shore track of the eddy over time (Fig. 9b). At each time step, the tracer concentrations were fit to a normal distribution:

$f(x)=\frac{1}{\sigma \sqrt{2 \pi}} e^{-\frac{(-x-\mu)^{2}}{2 \sigma^{2}}}$,

where $\mu$ and $\sigma^{2}$ are the mean and the standard deviation of the distribution. Because the eddy is mostly axisymmetric during its lifetime, to a first approximation, the 
Fig. 8 Passive tracer experiment (result for the tracer 4, i.e., tracers released in the core of $\mathrm{C} 01-2$, from the surface to $60-\mathrm{m}$ depth). a Passive tracer concentration integrated from 60-m depth to the surface represented at different times. b Time evolution of the passive tracer concentration, depth-integrated from $60 \mathrm{~m}$ to the surface, and alongshoreintegrated to represent the crossshore dispersion as the eddy travel offshore
Northern Origin (67\%)
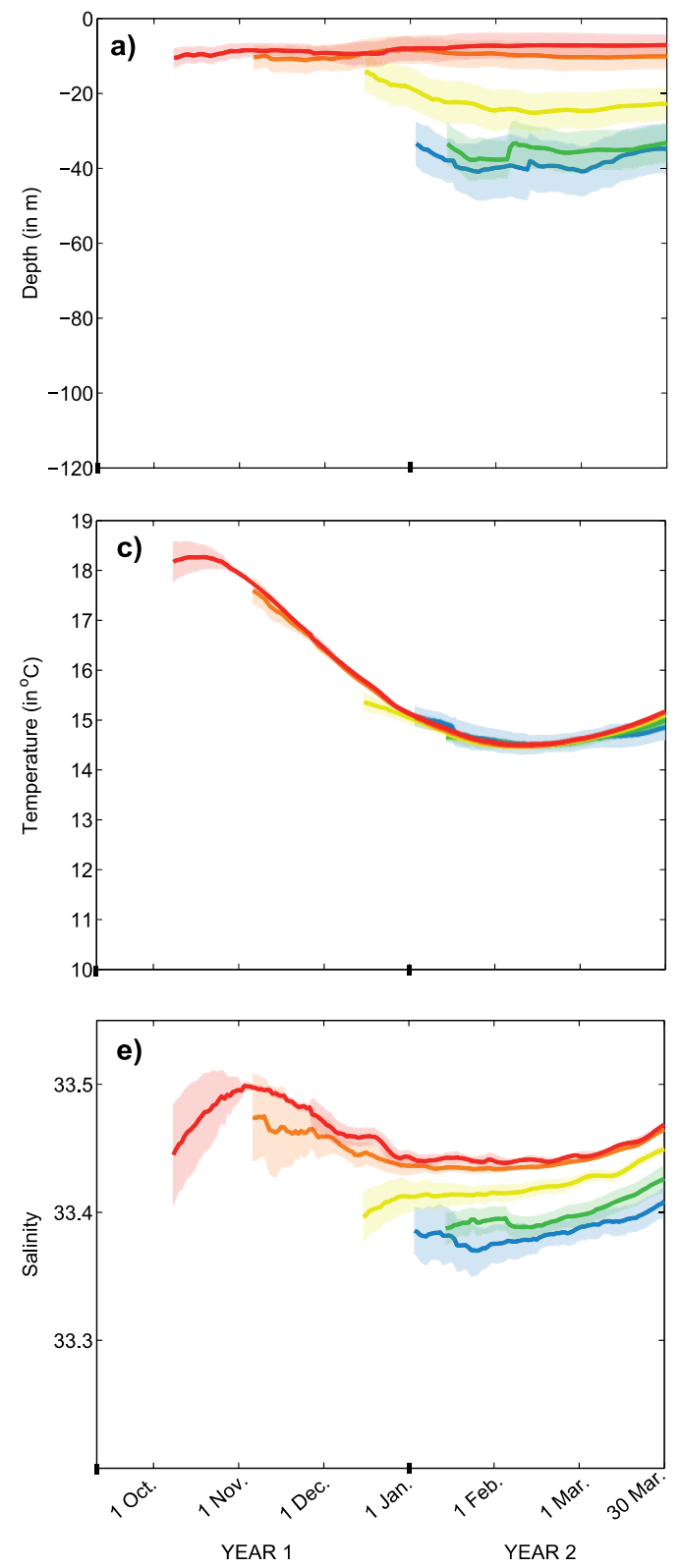

Southern Origin (33\%)

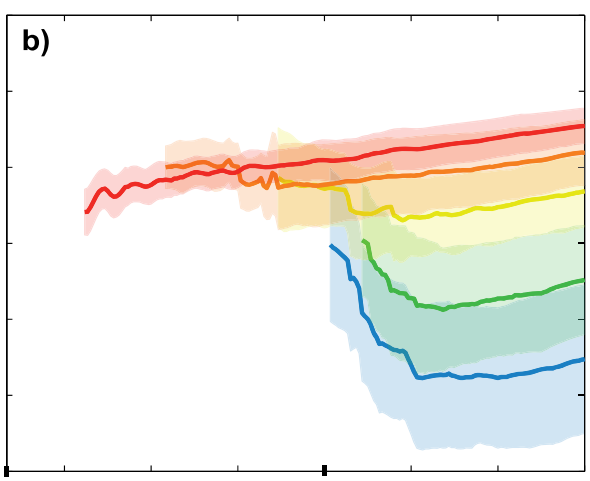

d)
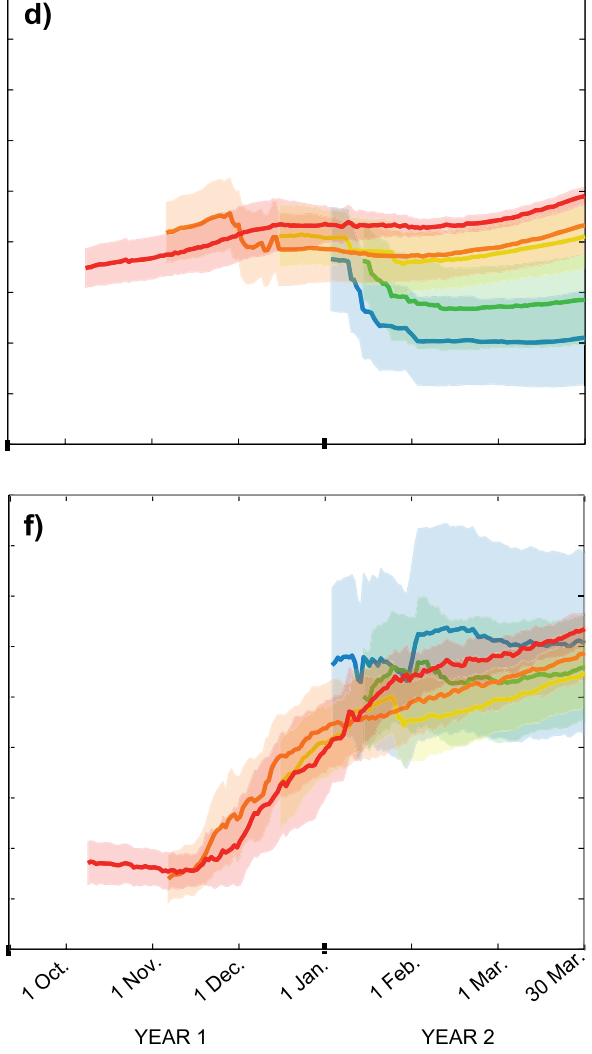

one-dimensional diffusion equation is a good descriptor of the diffusive processes in this particular case. The one-dimensional diffusion of an initial delta function distribution of a tracer is given by

$T(x, t)=\frac{1}{\sqrt{4 \pi D\left(t-t_{i}\right)}} e^{-\frac{\left(-x-x_{i}\right)^{2}}{4 D t}}$

with $T$ the tracer concentration, $x$ the cross-shore location and $t$ the time, $x_{i}$ and $t_{i}$ being the initial location and time of the eddy, and $D$ the horizontal diffusivity.

From these two equations, we find $2 \sigma^{2}=4 D t$, allowing us to estimate the diffusivity as $D=\sigma^{2} / 2 t$, with $\sigma^{2}$ the measured standard deviation of the tracer concentration distribution. We were able to assess the horizontal diffusivity $D$ for each experiment (i.e., different horizontal and vertical extents of tracers). In all cases (tracers 1 to 6), there is a period of relatively constant horizontal diffusivity (days 150-170), followed by an increase of the diffusivity associated with the eddy-eddy interactions that led to the dissipation of C01-2. The diffusivity in the eddy was $\sim 45 \mathrm{~m}^{2} \mathrm{~s}^{-1}$ when the tracer was released in the core (tracers $4,5,6$ ), or $\sim 130 \mathrm{~m}^{2} \mathrm{~s}^{-1}$ when the tracer was released over the entire eddy (tracers 1, 2, 3). These values are typical of background diffusivities used in numerical models such as ours with a grid spacing $\Delta x \sim$ $5 \mathrm{~km}$. Note, however, that in our simulation, diffusion arises from fourth-order truncation errors in the advection 
a)
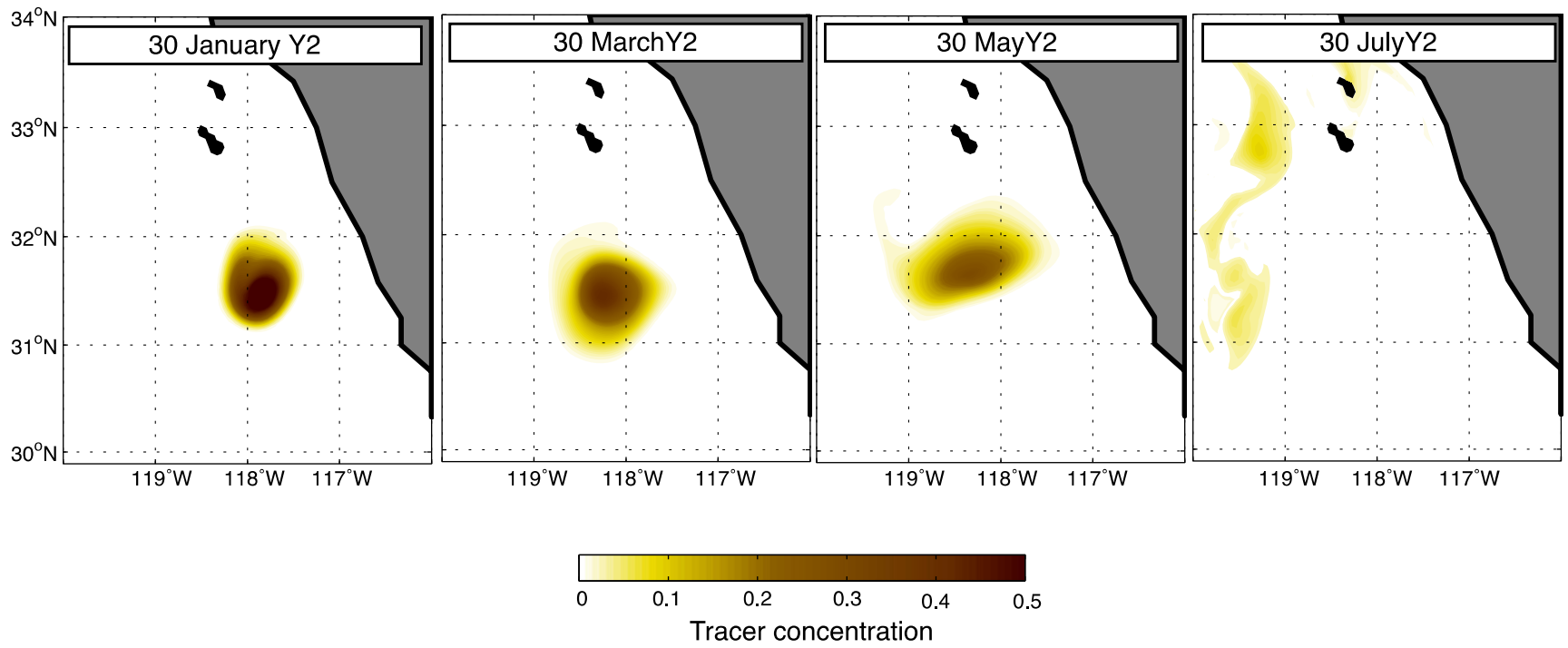

b)

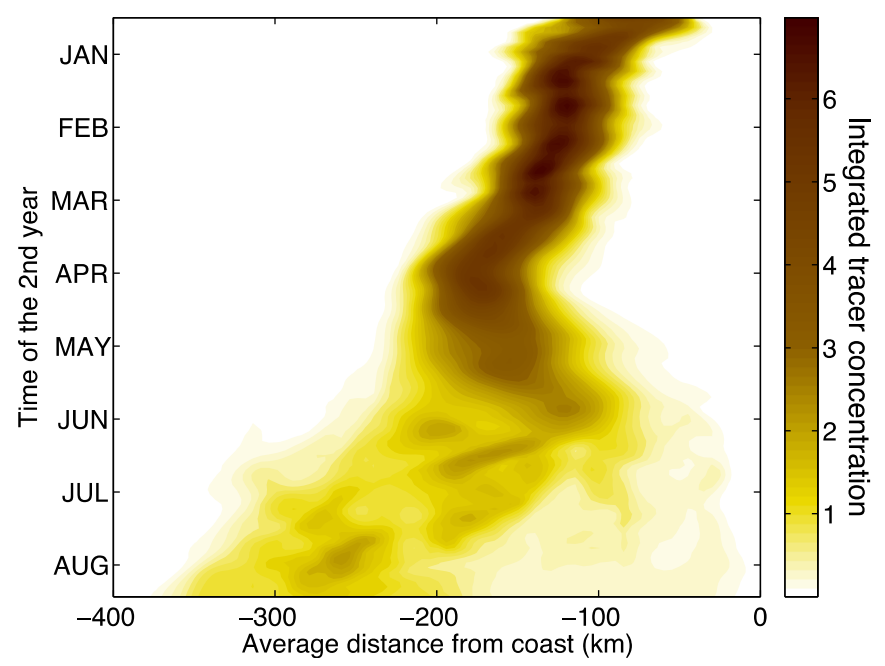

Fig. 9 Passive tracer experiment (result for the tracer released in the core, from surface to $60-\mathrm{m}$ depth). a Passive tracer concentration integrated from $60-\mathrm{m}$ depth to the surface represented at different time. b Time evolution of the passive tracer concentration, depth-integrated from $60 \mathrm{~m}$ to the surface, and alongshore-integrated to represent the crossshore dispersion as the eddy travel offshore operator, with adaptive diffusivity that scales as the modulus of velocity (Shchepetkin and McWilliams 1998), so a precise comparison is not possible. Nevertheless, the small magnitude of the tracer diffusivity we diagnosed confirms the limited role played by stirring and filamentation in and around the eddy (Nakamura 1996; Brannigan et al. 2015).

Thus, C01-2 was a very coherent eddy with very limited leakage-particularly in its core waters. The low advective and diffusive exchange of eddy waters with the surrounding waters creates a locally distinct environment in the eddy driving distinct local dynamics and fluxes of biogeochemical tracers (Chenillat et al. 2015).

\subsection{Biological impacts}

From the kinematic analyses of eddy $\mathrm{C} 01-2$, we found that it (i) formed near shore, trapping shallow coastal waters from the northern $\mathrm{CC}$ and nutrient-rich coastal waters from the southern CUC, and (ii) traveled offshore for at least 6 months with limited exchange with surrounding waters. Mesoscale eddies, and in particular cyclonic eddies, are known to play a fundamental role in modulating the biology of upwelling systems (Moore et al. 2007; Almazán-Becerril et al. 2012; Stramma et al. 2013; Chenillat et al. 2015, 2016). In-depth investigations of the effects of eddies on planktonic ecosystem dynamics were carried out for eddy C01-2 in Chenillat et al. (2015). The present analyses help us to understand the 
mechanics of how such mesoscale eddies are associated with enhanced biological activity, including enhanced chlorophylla concentrations and zooplankton biomass. As the eddy was generated near shore, nutrient-rich coastal waters and their associated biological materials became trapped in the eddy core. The varying proportions of coastal waters from the CC and the CUC modulate the initial nutrient concentrations within eddies at seasonal (Hickey 1979) and interannual scales (Combes et al. 2013). Because of their limited lateral exchange with surrounding waters, eddies efficiently transport material offshore. In addition to this cross-shore transport, local enrichment occurs in cyclonic eddy cores through vertical advection of nitrate from below the euphotic zone as a consequence of the uplift of the preexisting dome of the nitracline by Ekman pumping (Chenillat et al. 2015). Eddies are thus likely to locally fertilize the offshore environment when they decay and the waters disperse. On average, the offshore nutrient transport by eddies explain $\sim 50$ and $20 \%$ of the transport of nitrate and plankton, respectively, from the 200-km-wide coastal band; the remainder is exported by the mean offshore Ekman transport (Chenillat et al. 2016). Offshore transport by eddies is much faster than the Ekman transport $\left(\sim 2 \mathrm{~km}\right.$ day $^{-1}$ versus $<0.5 \mathrm{~m}^{-1 a y}{ }^{-1}$; Messié and Chavez 2015), and it is likely that most eddies that form ultimately contribute to enhancing the offshore nutrient flux.

These results also confirm that eddies can become ecological hotspots for both fish larvae and predators. Eddies maintain increased food availability, offer a relative stable environment while the eddy is in solid-body rotation, and are persistent enough (more than 50 days) to provide a suitable survival habitat for the development of larvae and juvenile fish (McClatchie 2014 and references therein).

\section{Summary and conclusions}

This study has focused on mesoscale activity in the Southern CCS using a 5-km horizontal resolution model. Using an eddy detection and tracking algorithm based on the Okubo-Weiss parameter, we found that mesoscale activity in the SCCS was dominated by cyclonic eddies, consistent with in situ data (Stegmann and Schwing 2007). On average, these eddies have a diameter of $50 \mathrm{~km}$ and can remain distinct for up to 190 days. The vertical structure of the average cyclonic eddy obtained from averaging $\sim 4000$ eddies shows a consistent doming of isopycnals in the eddy center, bringing deep, cold, salty, and nutrient-rich water closer to the surface. These cyclonic eddies are formed at the coast through current instabilities, mostly in the fall. Eddies consistently trapped water from the northwardflowing California Undercurrent and the southward-flowing shallow California Current, and transported these water masses offshore at a speed of $\sim 2 \mathrm{~km} \mathrm{day}^{-1}$.
To assess the details of the eddy kinematics, we focused on one particular cyclonic eddy, C01-2. Using a Lagrangian approach, we found that when $\mathrm{C} 01-2$ formed, its core contained $\sim 67 \% \mathrm{CC}$ and $\sim 33 \%$ CUC water. While the eddy was still a coastal meander, particles entering the eddy formed its core. As the eddy enlarged and detached from the coast, new particles from coastal (70-90\%) and to some extent non-coastal waters (10-30\%) wrapped around the core, forming concentric rings. The center of C01-2, composed of the oldest, coastal particles, was in an approximate solid-body rotation for about 2 months. The core was somewhat uncoupled from the edge of the eddy, which was composed of younger particles. These particles of coastal origin were transported in the eddy for at least 6 months as it moved offshore, showing that this coastal eddy was coherent and not very leaky.

Our results are sensitive to the numerical parameters and choices made for this study, in particular the horizontal model resolution and the absence of synoptic forcing. Eddy edges experience kilometer-scale secondary instabilities (e.g., see Fig. 16 in Capet et al. 2008d) that tend to be concentrated in (deep) mixed layers (Fox-Kemper et al. 2008). Such instabilities, which cannot be resolved in the present study with a horizontal resolution of $5 \mathrm{~km}$, could enhance the dispersion experienced by the near-surface, outermost particles of the eddy. Storms and ocean heat loss episodes would be needed to generate deep enough mixed layers to drive large submesoscale diffusivities $\left(\sim 30-50 \mathrm{~m}^{2} \mathrm{~s}^{-1}\right.$ in Capet et al. (2008a)) in the eddy periphery. Though such conditions would further affect our results through the associated vertical mixing within the eddy, they are rare in the SCCS (US GLOBEC 1992). In addition, we note that the cool surface temperatures of coastal cyclones naturally dampen heat losses. The fate of the released particles and the picture of eddy leakage we present may thus be accurate in the absence of major atmospheric disturbances, even for the eddy periphery.

The characteristics we have elucidated for cyclonic coastal eddies have important implications for biological production. Chenillat et al. (2015) followed this same eddy (C01-2) and found that (i) as it formed at the coast, it trapped nutrients that sustained a locally enhanced ecosystem through the eddy's lifetime, and (ii) it isolated the ecosystem in the eddy core from the surrounding waters, preventing horizontal losses and stimulating locally enhanced planktonic productivity through vertical advection of nutrients for several months.

Acknowledgments This work was supported by the California Current Ecosystem LTER site (NSF Award No. 1026607). FC thanks Mati Kahru (Scripps Institution of Oceanography, UCSD—mkahru@ucsd.edu) for providing satellite data. We thank the two anonymous referees for their insightful comment on the manuscript. The altimeter products were produced by Ssalto/Duacs and distributed by Aviso, with support from CNES (http://www.aviso.oceanobs.com/duac). The data used as boundaries and surface forcing for the model study are available from 
the Comprehensive Ocean-Atmosphere Data Set (COADS) (http://iridl. ldeo.columbia.edu/SOURCES/.COADS/), Advanced Very High Resolution Radiometer (AVHRR) (http://noaasis.noaa.gov/NOAASIS/ $\mathrm{ml} /$ avhrr.html), from Quick Scatterometer (QuikScat) (http://www. remss.com/missions/qscat), and Ocean General Circulation Model for the Earth Simulator (OFES) (http://www.jamstec.go.jp/esc/research/ AtmOcn/product/ofes.html). All the numerical runs were performed with the Caparmor high-performance computer facilities available at Ifremer. The numerical dataset that supports this article is available upon request to the authors.

\section{References}

Almazán-Becerril A, Rivas D, García-Mendoza E (2012) The influence of mesoscale physical structures in the phytoplankton taxonomic composition of the subsurface chlorophyll maximum off western Baja California. Deep Sea Res Part I Oceanogr Res Pap 70:91102. https://doi.org/10.1016/j.dsr.2012.10.002

Barth JA, Cowles TJ, Kosro PM, Shearman RK, Huyer A, Smith RL (2002) Injection of carbon from the shelf to offshore beneath the euphotic zone in the California Current. J Geophys Res 107(C6): 3057. https://doi.org/10.1029/2001JC000956

Batteen ML (1997) Wind-forced modeling studies of currents, meanders, and eddies in the California Current system. J Geophys Res 102(C1):985-1010

Batteen M, Cipriano N, Monroe J (2003) A large-scale seasonal modeling study of the California Current System. J Oceanogr 59(5):545-562

Beron-Vera FJ, Olascoaga MJ, Goni GJ (2008) Oceanic mesoscale eddies as revealed by Lagrangian coherent structures. Geophys Res Lett 35(12):L12603. https://doi.org/10.1029/2008GL033957

Blanke B, Raynaud S (1997) Kinematics of the Pacific equatorial undercurrent: an Eulerian and Lagrangian approach from GCM results. J Phys Oceanogr 27:1038-1053

Blanke B, Arhan M, Madec G, Roche S (1999) Warm water paths in the equatorial Atlantic as diagnosed with a general circulation model. J Phys Oceanogr 29(11):2753-2768. https://doi.org/10.1175/15200485(1999)029<2753:WWPITE $>2.0 . C O ; 2$

Bograd SJ, Lynn RJ (2003) Long-term variability in the Southern California Current System. Deep-Sea Res II 50:2355-2370. https://doi.org/10.1016/S0967-0645(03)00131-0

Bograd SJ, Mantyla AW (2005) On the subduction of upwelled waters in the California current. J Mar Syst 63(5):863-885. https://doi.org/10. 1357/002224005774464229

Brannigan L, Marshalla DP, Naveira-Garabatob A, Nurserc AJG (2015) The seasonal cycle of submesoscale flows. Ocean Model 92:69-84. https://doi.org/10.1016/j.ocemod.2015.05.002

Caldeira RMA, Marchesiello P, Nezlin NP, DiGiacomo PM, McWilliams JC (2005) Island wakes in the Southern California Bight. J Geophys Res 110(C11):C11012. https://doi.org/10.1029/2004JC002675

Capet XJ, Carton XJ (2004) Nonlinear regimes of baroclinic boundary currents. J Phys Oceanogr 34:1400-1409

Capet X, Marchesiello P, McWilliams JC (2004) Upwelling response to coastal wind profiles. Geophys Res Lett 31:L13311. https://doi.org/ 10.1029/2004GL020303

Capet X, Campos EJ, Paiva AM (2008a) Submesoscale activity over the Argentinian shelf. Geophys Res Lett 35(15):L15605. https://doi.org/ 10.1029/2008GL034736

Capet X, Colas F, Mcwilliams JC, Penven P (2008b) Eddies in eastern boundary subtropical upwelling systems. In: Hecht MW, Hasumi H (eds) Ocean Modeling in an Eddying Regime. AGU, Washington, D. C, pp 131-147. https://doi.org/10.1029/177GM10

Capet X, McWilliams JC, Molemaker MJ, Shchepetkin AF (2008c) Mesoscale to submesoscale transition in the California current system. Part I: flow structure, eddy flux, and observational tests. J Phys Oceanogr 38(1):29-43. https://doi.org/10.1175/2007JPO3671. 1

Capet X, McWilliams JC, Molemaker MJ, Shchepetkin AF (2008d) Mesoscale to submesoscale transition in the California Current System. Part II: frontal processes. J Phys Oceanogr 38(1):44-64. https://doi.org/10.1175/2007JPO3672.1

Carton JA, Giese BS (2008) A reanalysis of ocean climate using simple ocean data assimilation (SODA). Mon Weather Rev 136(8):2999 3017. https://doi.org/10.1175/2007MWR1978.1

Centurioni LR, Ohlmann JC, Niiler PP (2008) Permanent meanders in the California Current System. J Phys Oceanogr 38:1690-1710. https:// doi.org/10.1175/2008jpo3746.1

Chaigneau A, Gizolme A, Grados C (2008) Mesoscale eddies off Peru in altimeter records: identification algorithms and eddy spatiotemporal patterns. Prog Oceanogr 79(2-4):106-119. https://doi. org/10.1016/j.pocean.2008.10.013

Chaigneau A, Eldin G, Dewitte B (2009) Eddy activity in the four major upwelling systems from satellite altimetry (1992-2007). Prog Oceanogr 83(1-4):117-123. https://doi.org/10.1016/j.pocean.2009. 07.012

Chaigneau A, Le Texier M, Eldin G, Grados C, Pizarro O (2011) Vertical structure of mesoscale eddies in the eastern South Pacific Ocean: a composite analysis from altimetry and Argo profiling floats. J Geophys Res 116(C11):C11025. https://doi.org/10.1029/ 2011JC007134

Checkley DM, Barth JA (2009) Patterns and processes in the California Current System. Prog Oceanogr 83:49-64. https://doi.org/10.1016/j. pocean.2009.07.028

Checkley DM Jr, Dotson RC, Griffith DA (2000) Continuous, underway sampling of eggs of Pacifc sardine (Sardinops sagax) and northern anchovy (Engraulis mordax) in spring 1996 and 1997 off southern and Central California. Deep Sea Res. Part II Top. Stud. Oceanogr. 47:1139-1155

Chelton DB, Schlax MG, Samelson RM, de Szoeke RA (2007) Global observations of large oceanic eddies. Geophys Res Lett 34:L15606. https://doi.org/10.1029/2007GL030812

Chelton DB, Schlax MG, Samelson RM (2011) Global observations of nonlinear mesoscale eddies. Prog Oceanogr 91(2):167-216. https:// doi.org/10.1016/j.pocean.2011.01.002

Chenillat F, Franks PJS, Rivière P, Capet X, Grima N, Blanke B (2015) Plankton dynamics in a cyclonic eddy in the Southern California Current System. J. Geophys. Res. Oceans 120:5566-5588. https:// doi.org/10.1002/2015JC010826

Chenillat F, Franks PJS, Combes V (2016) Biogeochemical properties of eddies in the California Current System. Geophys Res Lett 43: 5812-5820. https://doi.org/10.1002/2016GL068945

Colas F, Capet X, McWilliams JC, Li Z (2013) Mesoscale eddy buoyancy flux and eddy-induced circulation in eastern boundary currents. J Phys Oceanog 43:1073-1095

Combes V, Chenillat F, Di Lorenzo E, Rivière P, Ohman MD, Bograd SJ (2013) Cross-shore transport variability in the California Current: Ekman upwelling vs. eddy dynamics. Prog Oceanogr 109:78-89. https://doi.org/10.1016/j.pocean.2012.10.001

Cushman-Roisin B (1994) Introduction to geophysical fluid dynamics. Prentice Hall, Englewood Cliffs, 320 pp

d'Ovidio F, Fernández V, Hernández-García E, López C (2004) Mixing structures in the Mediterranean Sea from finite-size Lyapunov exponents. Geophys Res Lett 31(17):L17203. https://doi.org/10.1029/ 2004GL020328

d'Ovidio F, De Monte S, Della Penna A, Cotté C, Guinet C (2013) Ecological implications of eddy retention in the open ocean: a Lagrangian approach. J Phys A Math Theor 46(25):254023. https://doi.org/10.1088/1751-8113/46/25/254023

Doglioli AM, Blanke B, Speich S, Lapeyre G (2007) Tracking coherent structures in a regional ocean model with wavelet analysis: 
application to Cape Basin eddies. J Geophys Res 112(C5):C05043. https://doi.org/10.1029/2006JC003952

Dong C, Idica EY, McWilliams JC (2009) Circulation and multiple-scale variability in the Southern California Bight. Prog Oceanogr 82(3): 168-190. https://doi.org/10.1016/j.pocean.2009.07.005

Emery WJ (2001) Water types and water masses. In: Steele JH, Thorpe SA, Turekian KK (eds) Encyclopedia of Ocean Sciences, vol 4. Academic, San Diego, pp 3179-3187

Emery WJ, Meincke J (1986) Global water masses: summary and review. Oceanol Acta 9(4):383-391

FAO (Food and Agriculture Organization of the United Nations) (2009) The State of the World Fisheries and Aquaculture 2008 (SOFIA), Rome, Italy. ISBN 978-92-5-106029-2

Flierl GR (1981) Particle motions in large-amplitude wave fields. Geophys Astropysical Fluid Dyn 18(1-2):39-74. https://doi.org/ 10.1080/03091928108208773

Fox-Kemper B, Ferrari R, Hallberg R (2008) Parameterization of mixed layer eddies. Part I: theory and diagnosis. J Phys Oceanogr 38(6): 1145-1165. https://doi.org/10.1175/2007JPO3792.1

Frenger I, Gruber N, Knutti R, Münnich M (2013) Imprint of Southern Ocean eddies on winds, clouds and rainfall. Nat Geosci 6(8):608 612. https://doi.org/10.1038/ngeo1863

Gruber N, Lachkar Z, Frenzel H, Marchesiello P, Münnich M, McWilliams JC, Nagai T, Plattner G-K (2011) Eddy-induced reduction of biological production in eastern boundary upwelling systems. Nat Geosci 4(11):787-792. https://doi.org/10.1038/ngeo1273

Hayward TL, Venrick EL (1998) Nearsurface pattern in the California Current: coupling between physical and biological structure. Deep Sea Res Part II Top Stud Oceanogr 45:634-658

Hickey BM (1979) The California current system — hypotheses and facts. Prog Oceanogr 8:191-279

Hickey BM (1998) Coastal oceanography of western North America from the tip of Baja California to Vancouver Island. In: Robinson AR, Brink KH (eds) The Sea, Volume 11: The Global Coastal Ocean: Regional Studies and Syntheses. Wiley, New York, pp 345-393

Hickey BM, Dobbins EL, Allen SE (2003) Local and remote forcing of currents and temperature in the central Southern California Bight. J Geophys Res 108(C3):3081. https://doi.org/10.1029/ 2000JC000313

Isern-Fontanet J, García-Ladona E, Font J (2003) Identification of marine eddies from altimetric maps. J Atmos Ocean Technol 20(5):772-778

Kahru M, Kudela RM, Manzano-Sarabia M, Mitchell BG (2012) Trends in the surface chlorophyll of the California Current: merging data from multiple ocean color satellites. Deep Sea Res. Part II Top. Stud. Oceanogr. 77-80:89-98. https://doi.org/10.1016/j.dsr2.2012.04.007

Kelly K, Beardsley R, Limeburner R, Brink K, Paduan J, Chereskin T (1998) Variability of the near-surface eddy kinetic energy in the California Current based on altimetric, drifter, and moored current data. J Geophys Res 103(C6):13,067-13,083

Kim H, Miller AJ, Neilson DJ, Mc Gowan JA (2005) Decadal variations of mixed layer depth and biological response. In: Sixth conference on coastal atmospheric and oceanic prediction and processes, 85th american meteorological society annual meeting, 9-13 January 2005, San Diego, CA (USA), pp 15-17

Kurian J, Colas F, Capet X, McWilliams JC, Chelton DB (2011) Eddy properties in the California current system. J Geophys Res 116(C8): C08027. https://doi.org/10.1029/2010JC006895

Lehahn Y, d'Ovidio F, Lévy M, Heifetz E (2007) Stirring of the northeast Atlantic spring bloom: a Lagrangian analysis based on multisatellite data. J Geophys Res 112(C8):C08005. https://doi.org/10.1029/ 2006JC003927

Logerwell EA, Lavaniegos B, Smith PE (2001) Spatially-explicit bioenergetics of Pacific sardine in the Southern California Bight: are mesoscale eddies areas of exceptional prerecruit production? Prog
Oceanogr 49(1-4):391-406. https://doi.org/10.1016/S00796611(01)00032-5

Marchesiello P, McWilliams JC, Shchepetkin AF (2001) Open boundary conditions for long-term integration of regional oceanic models. Ocean Model 3(1-2):1-20. https://doi.org/10.1016/S14635003(00)00013-5

Marchesiello P, McWilliams JC, Shchepetkin AF (2003) Equilibrium structure and dynamics of the California current system. J Phys Oceanogr 33:753-783

McClatchie S (2014) Regional fisheries oceanography of the California current system: the CalCOFI program. Springer, 235pp. ISBN 978 94-007-7222-9. https://doi.org/10.1007/978-94-007-7223-6

McWilliams JC, Flierl GR (1979) On the evolution of isolated nonlinear vortices. J Phys Oceanogr 9:1155-1182

Messié M, Chavez FP (2015) Seasonal regulation of primary production in eastern boundary upwelling systems. Prog Oceanogr 134:1-18. https://doi.org/10.1016/j.pocean.2014.10.011

Moore TS, Matear RJ, Marra J, Clementson L (2007) Phytoplankton variability off the Western Australian Coast: mesoscale eddies and their role in cross-shelf exchange. Deep-Sea Res II Top Stud Oceanogr 54(8-10):943-960. https://doi.org/10.1016/j.dsr2.2007. 02.006

Morrow R, Birol F, Griffin D, Sudre J (2004) Divergent pathways of cyclonic and anti-cyclonic ocean eddies. Geophys Res Lett 31(24): L24311. https://doi.org/10.1029/2004GL020974

Nakamura N (1996) Two-dimensional mixing, edge formation, and permeability diagnosed in an area coordinate. J Atmos Sci 53:1524 1537

Nencioli F, d'Ovidio F, Doglioli AM, Petrenko AA (2011) Surface coastal circulation patterns by in-situ detection of Lagrangian coherent structures. Geophys Res Lett 38(17):L17604. https://doi.org/10. 1029/2011GL048815

Okubo A (1970) Horizontal dispersion of floatable particles in the vicinity of velocity singularities such as convergences. Deep Sea Res Oceanogr Abstr 17:445-454

Owen RWJ (1980) Eddies of the California current system: physical and ecological characteristics. In: Power MD (ed) 2nd California Islands Multidisciplanary Symposium. Santa Barbara Museum of Natural History, Santa Barbara, pp 237-263

Pares-Sierra A, White WB, Tai C-K (1993) Wind-driven coastal generation of annual mesoscale eddy activity in the California current. J Phys Oceanogr 23(6):1110-1121. https://doi.org/10.1175/15200485(1993)023<1110:WDCGOA >2.0.CO;2

Pegliasco C, Chaigneau A, Morrow R (2015) Main eddy vertical structures observed in the four major eastern boundary upwelling systems. J Geophys Res Oceans 120:6008-6033. https://doi.org/10. 1002/2015JC010950

Penven P, Marchesiello P, Debreu L, Lefèvre J (2008) Software tools for pre- and post-processing of oceanic regional simulations. Environ Model Softw 23(5):660-662. https://doi.org/10.1016/j.envsoft. 2007.07.004

Samelson RM, Schlax MG, Chelton DB (2014) Randomness, symmetry, and scaling of mesoscale eddy life cycles. J Phys Oceanogr 44:1012-1029. https://doi.org/10.1175/JPOD-13-0161.1

Sangrà P, Pelegrí JL, Hernández-Guerra A, Igor A, Martín JM, MarreroDíaz A, Martínez A, Ratsimandresy AW, Rodríguez-Santana A (2005) Life history of an anticyclonic eddy. J Geophys Res 110(C3):C03021. https://doi.org/10.1029/2004JC002526

Sangrà $\mathrm{P}$, Pascual A, Rodríguez-Santana Á, Machín F, Mason E, McWilliams JC, Pelegrí JL, Dong C, Rubio A, Arístegui J, Marrero-Díaz Á, Hernández-Guerra A, Martínez-Marrero A, Auladell M (2009) The canary eddy corridor: a major pathway for long-lived eddies in the subtropical North Atlantic. Deep Sea Res. Part I Oceanogr Res Pap 56(12):2100-2114. https://doi.org/10. 1016/j.dsr.2009.08.008 
Shadden SC, Lekien F, Marsden JE (2005) Definition and properties of Lagrangian coherent structures from finite-time Lyapunov exponents in two-dimensional aperiodic flows. Phys D Nonlinear Phenom 212(3-4):271-304. https://doi.org/10.1016/j.physd.2005. 10.007

Shchepetkin AF, McWilliams JC (1998) Quasi-monotone advection schemes based on explicit locally adaptive dissipation. Mon Weather Rev 126:1541-1580

Shchepetkin AF, McWilliams JC (2005) The regional oceanic modeling system (ROMS): a split-explicit, free-surface, topographyfollowing-coordinate oceanic model. Ocean Model 9(4):347-404. https://doi.org/10.1016/j.ocemod.2004.08.002

Simpson JJ, Dickey TD, Koblinsky CJ (1984), An offshore eddy in the California Current System Part I: Interior dynamics, Prog Oceanogr 13:5-49

Sprintall J, Cronin MF (2001) Upper ocean vertical structure. In: Steele JH, Thorpe SA, Turekian KK (eds) Encyclopedia of ocean sciences. Academic, San Diego, pp 3120-3129
Stegmann PM, Schwing F (2007) Demographics of mesoscale eddies in the California Current. Geophys Res Lett 34(14):L14602. https:// doi.org/10.1029/2007GL029504

Stramma L, Bange HW, Czeschel R, Lorenzo A, Frank M (2013) On the role of mesoscale eddies for the biological productivity and biogeochemistry in the eastern tropical Pacific Ocean off Peru. Biogeosciences 10:7293-7306. https://doi.org/10.5194/bg-107293-2013

Strub PT, James C (2000) Altimeter-derived variability of surface velocities in the California Current System: 2. Seasonal circulation and eddy statistics. Deep Sea Res. Part II Top. Stud. Oceanogr. 47(5-6): 831-870. https://doi.org/10.1016/S0967-0645(99)00129-0

U.S. GLOBEC (1992) In: Mackas D, Strub T, Hunter J (eds) Eastern boundary current program: report on climate change and the California current ecosystem. U.S. Global Ocean Ecosystems Dynamics Report Number 7. University of California, Davis 99pp

Weiss J (1991) The dynamics of enstrophy transfer in two-dimensional hydrodynamics. Physica D 48(2-3):273-294 